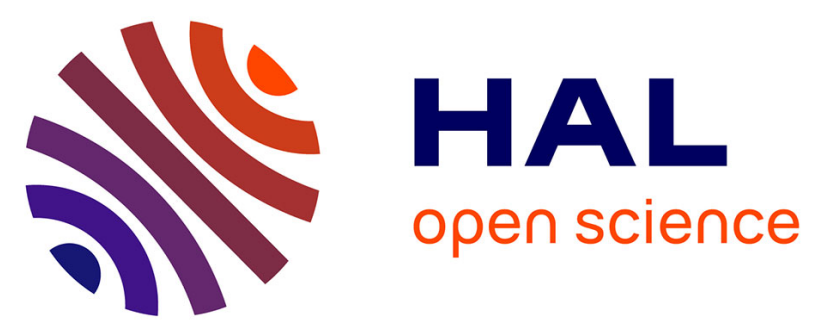

\title{
Conditional Induction of Math1 Specifies Embryonic Stem Cells to Cerebellar Granule Neuron Lineage and Promotes Differentiation into Mature Granule Neurons
} Rupali Srivastava, Manoj Kumar, Stéphane Peineau, Zsolt Csaba, Shyamala Mani, Pierre Gressens, Vincent El Ghouzzi

\section{To cite this version:}

Rupali Srivastava, Manoj Kumar, Stéphane Peineau, Zsolt Csaba, Shyamala Mani, et al.. Conditional Induction of Math1 Specifies Embryonic Stem Cells to Cerebellar Granule Neuron Lineage and Promotes Differentiation into Mature Granule Neurons. STEM CELLS, 2013, 31 (4), pp.652-665. 10.1002/stem.1295 . hal-02342661

\section{HAL Id: hal-02342661 \\ https://hal.science/hal-02342661}

Submitted on 2 Jun 2020

HAL is a multi-disciplinary open access archive for the deposit and dissemination of scientific research documents, whether they are published or not. The documents may come from teaching and research institutions in France or abroad, or from public or private research centers.
L'archive ouverte pluridisciplinaire HAL, est destinée au dépôt et à la diffusion de documents scientifiques de niveau recherche, publiés ou non, émanant des établissements d'enseignement et de recherche français ou étrangers, des laboratoires publics ou privés. 


\title{
Conditional induction of Math1 specifies embryonic stem cells to cerebellar granule neuron lineage and promotes differentiation into mature granule neurons
}

\author{
Rupali Srivastava $^{1,2,3}$, Manoj Kumar ${ }^{1,2}$, Stéphane Peineau ${ }^{1,2,4}$, Zsolt Csaba ${ }^{1,2}$, Shyamala Mani ${ }^{3,5^{*}}$, \\ Pierre Gressens ${ }^{1,2,6^{*}}$, Vincent El Ghouzzi ${ }^{1,2}$
}

1. Inserm, U676, Paris, France

2. Université Paris 7, Faculté de Médecine Denis Diderot, Paris, France

3. National Brain Research Centre, NBRC, Manesar, India

4. MRC centre for Synaptic Plasticity, School of Physiology and Pharmacology, Bristol, United Kingdom

5. Centre for Neuroscience, IISC, Bangalore, India

6. Centre for the Developing Brain, Imperial College, Hammersmith Campus, London, United Kingdom

* These authors have equally contributed to the manuscript

Corresponding author: Vincent El Ghouzzi, Inserm U676, Hôpital Robert-Debré, 48 Boulevard Sérurier, F-75019, Paris, France. E-mail: vincent.elghouzzi@inserm.fr, Phone: +331 40031973, Fax: +331 40031995

Running Head:

Key words:

Author's contribution:

Rupali Srivastava:

Manoj Kumar:

Stéphane Peineau:

Zsolt Csaba:

Shyamala Mani:

Pierre Gressens:

Vincent El Ghouzzi:
Math1 induction in granule neuron differentiation

Mouse embryonic stem cells, cerebellum, Math1, inducible system, neuronal lineage.

Generation, characterization, differentiation of mouse stem cells, real time PCR, immunocytochemistry, fluorescent microscopy, imaging, cell counting, collection, analysis and interpretation of data, writing of material and methods section

Stem cells culture, differentiation, immunocytochemistry, immunohistochemistry, confocal microscopy, imaging

Electrophysiological experiments and analyses

In vivo implantations, surgery

Conception of the study, data interpretation, manuscript writing

Data interpretation, financial support, final approval of manuscript

Conception and design of the study, western blots, data analysis and interpretation, financial support, manuscript writing, final approval of manuscript

\section{Sources of financial support:}

This study was supported by the Institut National pour la Santé et la Recherche Médicale (INSERM, France), the Centre National de la Recherche Scientifique (CNRS, France), Denis Diderot University (Paris7, France) and National Brain Research Centre (Haryana, India) and by grants from IFCPAR/CEFIPRA (project $\mathrm{N}^{\circ} 3803-3$ ), Department of Biotechnology (project $\mathrm{N}^{\circ}$ BT/PR11653/MED/31/602008), French National Research Agency (project ANR-09-GENO-007), the Princesse Grâce de Monaco Foundation and the Roger de Spoelberch Foundation. 


\section{ABSTRACT}

Directing differentiation of embryonic stem (ES) cells to specific neuronal subtype is critical for modeling disease pathology in vitro. An attractive means of action would be to combine regulatory differentiation factors and extrinsic inductive signals added to the culture medium. In this study, we have generated mature cerebellar granule neurons by combining a temporally controlled transient expression of Math1, a master gene in granule neuron differentiation, with inductive extrinsic factors involved in cerebellar development. Using a Tetracyclin-On transactivation system, we overexpressed Math1 at various stages of ES cells differentiation and found that the yield of progenitors was considerably increased when Math1 was induced during embryonic body stage. Math1 triggered expression of $M b h 1$ and $M b h 2$, two target genes directly involved in granule neuron precursor formation and strong expression of early cerebellar territory markers En1 and NeuroD1. Three weeks after induction, we observed a decrease in the number of glial cells and an increase in that of neurons albeit still immature. Combining Math1 induction with extrinsic factors specifically increased the number of neurons that expressed Pde1c, Zic1 and GABA $\alpha 6 \mathrm{R}$ characteristic of mature granule neurons, formed "T-shaped" axons typical of granule neurons and generated synaptic contacts and action potentials in vitro. Finally, in vivo implantation of Math1-induced progenitors into young adult mice resulted in cell migration and settling of newly generated neurons in the cerebellum. These results show that conditional induction of Math1 drives ES cells toward the cerebellar fate and indicate that acting on both intrinsic and extrinsic factors is a powerful means to modulate ES cells differentiation and maturation into a specific neuronal lineage. 


\section{INTRODUCTION}

The directed differentiation of embryonic (ES) cells to specific neuronal subtype is critical for modeling disease pathology in vitro especially because of the strong link between neurodevelopment and neurodegeneration [1]. A highly controllable in vitro system that recapitulates neurodevelopment would play an important role in distinguishing between cause and effect in disease progression and phenotype. In addition, directed differentiation of specific neurons in culture is very important for drug screens and therefore efficient ways of achieving this can substantially lower the cost of such screens [2]. Specification of neuronal subtype involves interpreting extrinsic signals in terms of cell intrinsic mechanisms that initiate subtype specific neuronal differentiation program [3]. Towards this end, specific extrinsic signals operate at different points during neuronal differentiation to specify neuronal subtype identity in a sequential manner [4]. The initial events of neuronal subtype specification involve specification of regional identity such as those that specify anterior-posterior and dorsal-ventral identity [5]. Within this domain other molecules specify the different types of neurons that must be generated from this region. These further regional subdivisions involve gradients of extrinsic signals that are read out as expression of transcription factors by the cell. This has been especially well elucidated in the spinal cord with respect to the specification of the various classes of cells that are present from dorsal to ventral in the spinal cord [4]. In addition, the specification of neuronal subtype involves combining subtype specific information with those that are part of a pan-neuronal differentiation program such as cell cycle exit and acquisition of mature neuronal morphology [6]. To understand subtype specification and mature neuronal differentiation, it is important to understand what part of the specification program becomes cell intrinsic and what part remains under the control of extrinsic cues.

The specification of granule neurons of the cerebellum is an interesting example of how neuronal subtype specification takes place. Unlike other glutamatergic neurons the specification of granule neurons has two distinct steps. Firstly, granule neuron progenitors (GNPs) are specified in the rhombic lip (RL) by factors such as BMP4 and FGF8 that induce the expression of the basic helix-loop-helix transcription factor Math1 in a domain that is positive for En1 and Pax6. Following this, a subset of Math1 positive precursors migrate out of the RL taking a dorsal route and cover the cerebellar anlage to populate the outer external granule layer (EGL) where they subsequently proliferate, differentiate and tangentially migrate within the EGL. Finally, they migrate inwards to form the mature granule neurons of the inner granule layer (IGL) [7]. In the absence of Math1, granule neurons fail to form [8]. Furthermore, extrinsic signals that control the proliferation and maturation of GNPs have been well characterized [9]. Given this unique spatial temporal separation 
of GNPs development, our aim was to see how much of granule neuron identity in ES cells is specified by the cell intrinsic transcription factor Math1 and how much is dependent on external cues. Previous studies have established that markers of granule neurons can be induced in mouse and human ES cells by external signals $[10,11,12]$. However, the contribution of Math1 to the differentiation process is not known. In this study, we hypothesized that Math1 could be sufficient to specify ES cells to GNPs thus promoting their differentiation and maturation upon subsequent addition of specific growth factors. To address this hypothesis, we created an inducible system that allowed us to induce Math1 transiently. We then allowed these cells to undergo terminal neuronal differentiation in the absence or presence of extrinsic signals and compared granule neuron specific as well as pan neuronal gene expression to delineate the contribution of Math1 and that of extrinsic factors to the efficiency of deriving mature granule neuron from ES cells.

\section{MATERIALS AND METHODS}

\section{Construction of lentivector and lentivirus production}

The insulated lentivector pLTET-Math1 was engineered by modification of pLTET-Luc (gift from Dr. Goodell) by site-directed mutagenesis (Stratagene, 200522) to get two unique restriction sites (EcoR1/Cla1) flanking Luciferase gene. Math1 full-length cDNA was amplified from the cDNA IMAGE clone 4218223 (OriGene, MC208159, NM_007500) with the 5'-EcoR1 and 3'-Cla1 overhangs. The amplicon and modified pLTET-Luc were digested with EcoR1 and Cla1. Following ligation of pLTET with Math1, the final vector was used to transform Stbl2 competent cells (Invitrogen 10268-019). Positive clones were checked by digestion with EcoR1/Cla1 and direct sequencing. Production and titration of lentiviruses were performed by Sigma-Aldrich and transduction-ready viral particles $\left(1.10^{8} \mathrm{TU} / \mathrm{ml}\right)$ were stored at $-80^{\circ} \mathrm{C}$.

\section{Generation of the Math1 inducible ES cell line}

Mouse embryonic stem cells (ESD3) were modified in a two-step process to generate cell lines with Tet-ON system of gene expression, which conditionally expresses Math1 upon doxycycline exposure (Fig.1A). In the first step, the undifferentiated cells were transduced with lentivirus containing pLTET-Math1. In this lentivector, the TRET promoter allows doxycycline-dependant control of the Math1 gene and the strong mammalian promoter EF1 $\alpha$ constitutively drives the expression of DsRedEX, a variant of red fluorescent protein with increased solubility and faster maturation [13]. Passage 11 cells were plated at a density of $8 \times 10^{4}$ per well in a gelatin coated 96 well plate and allowed to grow for $20 \mathrm{hrs}$. Following a $15 \mathrm{~min}$ treatment with $8 \mu \mathrm{g} / \mathrm{ml}$ Polybrene (Sigma, H9268) at $37^{\circ} \mathrm{C}$, cells were transduced with the lentivirus at a multiplicity of infection 
(MOI) of 10 for $24 \mathrm{hrs}$. The DsRedEx positive cells were first manually enriched and then clonally selected by serial dilution method to get pure TRET-Math1 clones.

In the second step, the TRET-Math1 clones were stably transfected with the modified form of the pTet-On Advanced regulator plasmid (Clontech, 630930) encoding the transactivator protein rtTA2s-M2 under EF1 $\alpha$ promoter. In the presence of doxycycline, rtTA2s-M2 binds the TRET promoter and activates transcription of the downstream gene. Around subconfluent passage 5 TRET-Math1 cells were transfected in 12-well culture plates using $4 \mu 1$ Lipofectamine2000 (Invitrogen 11668-019) with $2 \mu \mathrm{g}$ of linearized plasmid. Selection of successfully transfected cell was done with $400 \mu \mathrm{g} / \mathrm{ml}$ Geneticin (Invitrogen, 11811-031), followed by serial dilution for clonal selection. Many clones of Math1-inducible ES cells were obtained and assessed by real time PCR for their ability to over-express Mathl in undifferentiated stage upon Doxycycline treatment. Three different lines, namely clone 1.2 , clone 1.3 and clone 2.8 were selected for experiments as they gave the maximum levels of expression.

\section{Culture of undifferentiated Math1-inducible ES cells}

Undifferentiated cells were grown on $0.1 \%$ gelatin-coated plates in the presence of ESD3 media containing 15\% FBS (Hyclone, SH30070.03), 1X Glutamax (Gibco, 35050-038), 1X MEM-NEAA (Gibco, 11140-050), 1X Pen-strep (Gibco, 15070-063), 9.9×10-5 molar $\beta$-Mercaptoethanol (Gibco, 21985-023), $10^{3}$ units/ml Leukemia inhibitory factor (Chemicon, ESG1107) in DMEM (Sigma, D5796). For passaging, 0.25\% Trypsin EDTA was used (Sigma, T-4049).

\section{Primary Culture of neonatal cerebellar granule neurons}

Primary cultures of neonatal cerebellar granule neurons were obtained by following a procedure adapted from [14] Briefly, cerebella were isolated from P5 OF1 mouse brains and dissected under microscope to remove meninges. Tissue was treated in PBS/Glucose containing $0.25 \%$ trypsine EDTA (Sigma, T-4049) and 1mg/ml DNase1 (Sigma, DN25) and dissociated manually by repeated pipetting with a fire polished glass pipette, centrifuged, then again dissociated in the presence of DNase1 and re-centrifuged. Cell pellet was resuspended in BME media containing 1\% FBS, 45\% Glucose, 1X Glutamax, 1X Pen-strep, 1X B27 supplement (Gibco, 17054-044) and plated on wells coated with 30ug/ml polyornithine (Sigma, P3655) and 5ug/ml laminin (Sigma, L2020). Media was changed every alternate day and cells fixed and used after 7 to 9 days.

\section{Differentiation of the Math1-inducible ES cells}


For basic neuronal differentiation (referred as basal condition in Fig.1B) [14], undifferentiated cells (UD) were differentiated over a period of 31 days following the successive steps of early embryonic bodies (eEBs), late embryonic bodies (lEBs), neurospheres (NS) and ultimately final differentiation stage (FD). To form EBs, passage 15-18 undifferentiated cells were seeded at the density of $28 \times 10^{5}$ on $60 \mathrm{~mm}$ low adherent culture plates in ESIM media containing 10\% FBS, 1X Glutamax, 1X Penstrep, 1X MEM-NEAA in DMEM either in the absence (eEBs) or presence (lEBs) of 1mM retinoic acid (RA, Sigma, R-2625). 14mm glass coverslips were coated with $30 \mu \mathrm{g} / \mathrm{ml}$ p-ornithine (Sigma, P3655 ) for $4 \mathrm{hrs}$, washed, UV treated and incubated overnight at $37^{\circ} \mathrm{C}$ with $5 \mu \mathrm{g} / \mathrm{ml}$ laminin (Sigma, L-2020) made in PBS. The EBs were resuspended in NS media, plated on coated coverslips and grown for ten days. NS media consisted of 1X Glutamax, 1X Pen-strep, 1X ITS supplement (Gibco, 51500-056), 20ng/ml bFGF (R\&D Systems, 234-FSE-025/CF) in DMEM-F12 (Gibco, 11330-032). For final stage, the neurospheres were grown in media consisting of $1 \mathrm{X}$ Glutamax, $1 \mathrm{X}$ Pen-strep, 1X N2 supplement (Gibco, 17502-048), 1X B27 supplement (Gibco, 17054-044), 1 $\mu \mathrm{g} / \mathrm{ml}$ Laminin in Neurobasal-A media (Gibco, 10888-022) for 14 days.

To obtain a specific cerebellar granule cell differentiation, the cells were cultured as described above, along with the sequential addition of specific inducible factors, adapted with modifications from Salero \& Hatten [12] (referred to as basal condition + growth factors cocktail in Fig.5A). All factors except Wnt1 (Abcam) were purchased from R\&D systems. Factor concentrations used were according to [12]. Fresh media was replenished every alternating day for the respective stage.

\section{Doxycycline induction of Math1 overexpression}

Math1 induction was performed at various stages in the basal conditions either with or without the growth factors cocktail. Doxycycline (Sigma, D-9891) was reconstituted in sterile water, filter sterilized and added in the stage specific media to get the final concentration of $2 \mu \mathrm{g} / \mathrm{ml}$. For seven days experiments, Doxycycline was replenished every alternating day together with fresh ESIM media alone or with supplements according to the experiment. To stop the induction, old media was removed, cells given two $1 \mathrm{X}$ PBS washes, and finally replenished with the next stage media.

\section{RNA extraction and relative quantification of gene expression by real time PCR}

Total RNA was extracted from the cells collected at the end of UD, eEB, IEB, NS and FD stages using TRI reagent (Sigma, T9424). 0.1\% DEPC (Sigma, D5758) treated autoclaved water was used for all the molecular work. RNA was quantitated using Nanodrop1000 spectrophotometer, treated with DNase (Roche, 04716728001) and again quantitated. 250ng of total treated RNA was used to synthesize cDNA (Bio-Rad, 170-8891) in 20 1 reaction mix according to the manufacturer's 
protocol. Quality of cDNA was validated by semi-quantitative PCR (Taq DNA polymerase: Roche, 11647679001; dNTP set: Amersham Biosciences, 27-2035-01) for the amplification of housekeeping gene HPRT, that was chosen as the internal control for real time PCR on the basis of its stable expression during all the stages of stem cell differentiation. PCR products were checked on a $2 \%$ agarose gel.

$\begin{array}{cccccccc}\text { Primers } & \text { (Table 1) } & \text { were } & \text { either designed } & \text { using } & \text { program } & \text { PRIMER3 } \\ \text { (http://frodo.wi.mit.edu/primer3/) } & \text { or } & \text { chosen } & \text { from } & \text { Primer } & \text { Bank } & \text { site }\end{array}$ (http://pga.mgh.harvard.edu/primerbank/), and conditions standardized by semi-quantitative PCR. 2X iQ-SYBRGreen Supermix (Bio-Rad, 170-8885) was used for real time PCR with the following conditions: $95^{\circ} \mathrm{C} 3 \mathrm{~min} / 45$ cycles $\left[95^{\circ} \mathrm{C} 30 \mathrm{sec}\right.$, Annealing temperature $\left.30 \mathrm{sec}, 72^{\circ} \mathrm{C} 35 \mathrm{sec}\right]$. Dissociation curve was generated for checking the amplification specificity. The standard curves for both internal control and gene of interest were generated to determine the PCR efficiency. All the samples were run in triplicate and negative controls without cDNA were run each time together with the samples for both internal control (HPRT) and gene of interest. The data was analyzed by comparative CT method [15] to determine fold differences in expression of target genes with respect to the internal control.

\section{Immunocytochemistry and Immunofluorescence microscopy}

Cultures were fixed for 20min with 4\% Paraformaldehyde. For immunocytochemistry, the cells were permeabilized with $0.3 \%$ TritonX-100 for $15 \mathrm{~min}$, washed, blocked for $1 \mathrm{hr}$ with $4 \% \mathrm{BSA} / 10 \%$ serum in PBS and incubated with primary antibody overnight at $4{ }^{\circ} \mathrm{C}$. Following washing, cells were treated with secondary antibody (1:1000 dilution) for $1 \mathrm{hr}$ in dark at room temperature. For immunocytochemistry on embryonic bodies, EBs were collected in a $1.5 \mathrm{ml}$ microfuge tube and allowed to settle properly by gravitational pull. The media was discarded and EBs were given one 1X PBS wash. The PBS was removed and EBs were incubated in 4\% Paraformaldehyde for 20min at room temperature, after which four 1X PBS washes were given. Whole EBs were stained by immunofluorescence similarly in the microfuge tube. For co-stainings, the second antibody was added and processed as for the first. Cells were finally mounted with mounting media containing DAPI (Vector labs, H-1200). Specificity of the stains was checked using non-relevant primary antibodies that don't react with any antigen (mouse IgG1 isotype control (Abcam, ab126026) and rabbit IgG isotype control (Abcam, ab27478)) as shown in supporting information Figure 7. Antibodies and dilutions used are listed in Table 2. All images were captured on Zeiss microscope IMAGER.Z1, using the Apotome imaging system coupled to AxioCam MRm and the Axiovision Rel.4.8 software. 


\section{Cell implantation and immunohistochemistry}

Clone 1.2 cells were induced with Doxycycline during EB stage in the presence of growth factors, as described in Fig.5A and collected at NS stage. Cells were trypsinized and made single cell suspension in PBS. P60 adult OF1 mice $(n=5)$ under Isoflurane anaesthesia were mounted on a stereotaxic frame. Injections were made with glass micropipettes implanted into the cerebellum (lambda, $-2 \mathrm{~mm}$; lateral, $0 \mathrm{~mm}$; depth, $-2.2 \mathrm{~mm}$ ). A volume of $2 \mu 1$ containing $4 \times 10^{5}$ cells was injected at a rate of $0.134 \mu 1$ per min. The micropipette was left in place for an additional 3 min to reduce backflow. One week after implantation, mice were deeply anesthetized and transcardially perfused with $0.9 \% \mathrm{NaCl}$ for $1 \mathrm{~min}$ followed by cold $4 \%$ paraformaldehyde. Brains were then dissected out, post fixed with same fixative overnight at $4^{\circ} \mathrm{C}$, cryoprotected with $30 \%$ sucrose in $0.12 \mathrm{M}$ phosphate buffer and frozen at $-45^{\circ} \mathrm{C}$ in isopentane for $3 \mathrm{~min}$ before sectioning. $30 \mu \mathrm{m}$ sagittal floating sections were prepared using a freezing microtome and collected in PBS. Implanted cells contain the DsRed gene under the control of the constitutive EF1 $\alpha$-promoter (Fig.1A) and although natural fluorescence disappeared upon neuronal differentiation, DsRed-expressing cells could still be revealed using an anti DsRed antibody. For immunostaining, sections were first treated with citrate buffer at $80^{\circ} \mathrm{C}$ for antigen retrieval. After several washes in PBS, they were incubated for $1 \mathrm{hr}$ at room temperature in blocking buffer ( $2 \%$ BSA, 5\% serum, 0.3\% Triton in PBS), followed by primary antibody incubation in similar buffer with $0.1 \%$ Triton at $4^{\circ} \mathrm{C}$ overnight. Then sections were rinsed in PBS and incubated for $1 \mathrm{hr}$ in dark with the secondary antibody. After several washes in PBS, sections were counterstained with DAPI for $1 \mathrm{~min}$ and mounted with anti-fading medium (DAKO).

\section{Cell counting}

Cell countings were performed using ImageJ and Adobe Photoshop. For counting cells positive for a marker with respect to total number of cells (DAPI-positive), 25-35 random fields (depending on the cell density, covering the maximum coverslip) were captured under $40 \mathrm{X}$ and counted; for finding cells positive for a marker with respect to Tuj1, MAP2 or Nestin, seven random fields were captured on the coverslip and counted. For EBs imaging and cell counting, z-stack images at an interval of $1 \mu \mathrm{m}$ for each EB were taken at 20X magnification. For cell counting one image out of the stack of around 14 images of each EB containing defined and countable DAPI positive nucleus and properly focused $\mathrm{Ki}-67$ or Clv caspase 2 positive cells was selected and the cells were manually counted with the image-J software. All the counts were repeated for six independent experiments.

\section{Western blot analyses}


For Math1 detection, control tissue samples were dissected out from P4 mice cerebella, sonicated in ice-cold lysis buffer $(50 \mathrm{mM}$ Tris- $\mathrm{HCl}, \mathrm{pH} 7.5,150 \mathrm{mM} \mathrm{NaCl}, 0.5 \%$ NP40, $0.25 \%$ sodium deoxycholate, protease inhibitors) and centrifuged. Clones 1.2, 1.3 and 2.8 were used for producing EBs for 7 days in control and Dox-induced conditions. Proteins were extracted from EBs in the same buffer. Protein concentrations were determined according to Bradford [16]. Lysates were denatured, separated by SDS-PAGE and transferred to PVDF membranes (Millipore, RPN303F). Membranes were probed with either anti-Math1 (Acris, AP00308PU-N dilution 1:200), or antiActin antibodies (Millipore, MAB1501, dilution 1:10000) and signal was detected by enhanced chemiluminescence.

\section{In vitro Electrophysiology}

Experiments were performed on stem cell cultures plated on $40 \mathrm{~mm}$ culture dishes. Cells were continuously superfused in recording solution which comprised $(\mathrm{mM}): \mathrm{NaCl}, 124 ; \mathrm{KCl}, 3$; NaHCO3, 26; NaH2PO4, 1.25; $\mathrm{CaCl} 2,2$; MgSO4, 1; glucose, 10. Visually-guided, whole-cell recordings were obtained at room temperature from the soma of neuronal-like cells using patch electrodes (4-6 MOhms) that contained (mM): KCl, 140; HEPES, 10; NaCl, 8; EGTA, 0.5; MgATP, 4; Na-GTP, 0.3. Voltage was recorded on-line using current-clamp techniques. Depolarisations by current injection were performed to induce action potential. Data were stored and analysed using the LTP Program [17, 18].

\section{Statistical analyses}

Quantitative data are expressed as mean \pm SEM for each treatment group. Results were compared using the Mann-Whitney comparison test (GraphPad Prism Software). A two-tailed $p<0.05$ was considered as significant.

\section{RESULTS}

Math1 expression can be induced in a temporally controlled manner during ES cell differentiation.

Math1 is developmentally regulated in GNPs and therefore we developed an inducible gene expression system whereby the expression of this transcription factor could be temporarily regulated. To this end we generated clone 1.2, a stable mouse ES cell line capable of inducing Math1 expression in a reversible manner through the control of a stably expressed doxycycline (Dox)-regulated reverse transcriptional transactivator (rtTA2s-M2) (Fig.1A). Such improved TET regulators have been used for conditional gene expression in several ES cells models and have 
proved to be highly efficient without altering the pluripotency of the undifferentiated cells [13]. Consistent with this, undifferentiated ES cells from our clone 1.2 cultures were found to express extensively the pluripotency-related markers SSEA1 and Oct4, suggesting that, like native ESD3 cells, they have kept their pluripotency (Supporting Information Fig.1). Next, we quantified the ability of our transgene expression system to induce Math1 expression at different stages of ES cell differentiation. The differentiation protocol giving the five different stages at which Dox was added to induce transgene expression is schematized (basal condition, Fig.1B) and the detailed methods for achieving this are given in the methods section. Following addition of Dox for 48 hours at the beginning of each of these five stages, we either collected the cells pellets directly after induction or cells were washed to remove Dox and let the differentiation reach the final stage. Dox addition was able to induce transgene expression at all stages of differentiation and removal of Dox led to a return of Math1 expression that were comparable to that of pre-induction levels (Fig.1C) thus showing that we had a temporally regulated highly inducible transgene system. Quantitative PCR showed that induction of Math1 using our system was most efficient at the embryonic bodies (EBs) stage and less efficient at undifferentiated (UD) and final differentiation (FD) stage (Fig.1D). Immunocytochemistry and western blot analysis on late EBs stage cells confirmed that the induction led to increased Math1 protein (Fig.1E-F). Together, these data indicate that we derived an ES cell line able to drive Math1 overexpression upon Dox induction and that conditional Mathl induction is most efficient during EBs stage.

\section{Mbh1 and Mbh2 are induced by Math1 in a dose dependent manner and are maintained during ES cells differentiation}

To test whether the induction of Mathl resulted in the activation of genes that are important for the specification of granule neuron identity, we looked at the Bar-class homeobox genes Mbhl and Mbh2 that are the downstream targets of Math1 [19, 20]. We found a significant stimulation of Mbhl and Mbh2 when Math1 was induced at early EBs (eEBs) and late EBs (lEBs). Taking advantage of the fact that induction of the transgene was most efficient at EBs, less efficient at neurosphere (NS) and not very efficient at other stages, we looked at the dose dependent effect of Math1 expression on Mbh1 and Mbh2. Results showed that the induction of Mbh1 and Mbh2 was dependent on the levels of Math1 (Fig.1D and Fig.2A).

We next tested whether the expression of Mbh1 and Mbh2 persists once induced by Math1. Dox was added during the whole EB stage (eEBs+lEBs) and expression of Mbh1 and Mbh2 was analyzed. From seventh day to the end of the differentiation process, both $M b h 1$ and $M b h 2$ expression was increased by 2-3 folds (Fig.2B). Thus, although the induction of Math1 was transient, the downstream targets $M b h 1$ and Mbh2 stayed on throughout the differentiation 
suggesting that once the downstream program is activated it is independent of Mathl expression. Immunocytochemistry experiments using antibodies against Mbh1 and Mbh2, 17 days after initiation of induction confirmed that induced neural precursors were much more immunoreactive than non-induced controls (Fig.2C). Together, these data indicate that Mathl induction at EBs stage is sufficient to trigger a persistent activation of target genes required for specification of granule neurons identity, during ES cell differentiation.

Transient expression of Math1 during the EBs stage leads to increased neuronal and decreased glial differentiation.

To determine the effects of Mathl transient expression on neuronal differentiation, we induced Math1 during EBs stage and analyzed the cells at the end of FD stage. Quantitative PCR showed an increase in the neuronal markers Tuj1 and MAP2, and a decrease in GFAP and Olig2 upon Math1 induction (Dox) (Fig.3A). Immunocytochemistry confirmed an increase in the number of Tuj1 and MAP2 positive cells and a decrease in GFAP positive cells (Fig.3B-C). We did not detect a decrease in the number of Olig2 positive cells possibly because very few cells express Olig2 under our differentiation conditions. These data were confirmed in two additional independent clones, clone 1.3 and clone 2.8 (Supporting Information Fig.5). Interestingly, the total number of neural cells remained unchanged in induced and control conditions $(73.60 \%$ and $74.51 \%$ of total cells respectively, Fig. 3B). To check that these results were not due to some "pro-neural" characteristics of our clones, we compared their neural properties to those of native ESD3 and ESB6 cells, two unmodified mouse ES cell lines. In all cell lines, expression levels of the neural markers Tuj1 (32.2$37.9 \%$ ), GFAP (33.6-38.6\%) and Olig2 (5.7-9.7\%) were measured in comparable ranges upon differentiation in basal conditions (Supporting Information Fig.4A). The proportion of neural cells versus non-neural cells was almost identical between clone 1.2 and its parental ESD3 cell line while ESB6 cells showed a higher trend in favor of neural differentiation (Supporting Information Fig.4AB). Furthermore, although Ki67 was slightly increased at the end of EBs stage, Math1 expression did not result in an increased cell proliferation at NS stage (Supporting Information Fig.2C) nor later. Further there was no increase in apoptotic cell death at any stage tested, as assessed by cleaved caspase-3 immunostaining (Supporting Information Fig.2C). Taken together these observations suggest that transient activation of Mathl during an early stage of ES cell differentiation results in Tuj1-positive cells being produced at the expense of GFAP-positive cells.

Transient expression of Math1 results in the differentiation of neurons that express granule cell markers in the correct temporal sequence 
Since transient Mathl expression resulted in an increase in neuronal differentiation, we asked whether it was sufficient to activate the expression of markers of granule neuron subtype. Quantitative PCR showed an increase in the mRNA levels of Zic1 and Pde1c, that are early markers of granule neuron subtype which remain expressed throughout differentiation, of TAG1, expressed in migrating post-mitotic granule neurons and finally of GABA $\alpha 6$ r expressed specifically in mature granule neurons (Fig.4A). To check if indeed GABAa6r was expressed in mature neurons we compared the expression of GABA $\alpha 6 \mathrm{r}$ in Tuj1-expressing and in MAP2-expressing neurons after terminal differentiation. Results showed that there was an increase in the number of MAP2 positive cells expressing GABA $\alpha 6 \mathrm{r}$, many with higher intensity and that the number of Tuj 1 positive cells expressing GABAa6r remained the same as in non-induced condition (Fig.4B-C). However, Zic1 and Pde1c had increased expression in Tuj1 positive cells that is an earlier marker for neuronal differentiation (Fig.4B-C). Although not apparent at RNA level, Zic2 also showed an increase in induced condition in Tuj1 positive cells (Fig.4A-C). Thus, transient Math1 expression resulted in an increase in the expression of GABA $\alpha 6 \mathrm{r}$ only in mature neurons whereas earlier markers were found increased in immature neurons suggesting that the timing of expression of the various subtype specific markers was recapitulated during ES cell differentiation. Consistent with this idea, the expression of engrailed (En1) and NeuroD1, specific of early progenitors was found increased at the late EB stage but not at later stages (Supporting Informations Fig.2B and 3B). Finally, induction of Math1 had no effect on the number of cells expressing the mature pan-neuronal marker MAP2 (Fig.4B), indicating that the increased number of MAP2 neurons shown in figure 3 directly resulted from the increase of Tuj1-expressing cells upon Math1 activation. Similar data were obtained upon induction of the two other clones 1.3 and 2.8 (Supporting Information Fig.6). Taken together these results suggest that transient induction of Math1 not only causes more cells to become neuronal but also is sufficient to direct cells into neurons that express granule cell markers in the correct temporal sequence.

\section{Maturation of granule neurons requires extrinsic signals}

Although induction of Math1 resulted in a significant increase in the number of mature neurons expressing MAP2 and GABA $66 \mathrm{r}, 40 \%$ of the Tuj1-expressing cells were still negative for MAP2 (Fig.4B) and 65\% were found positive for Pax6, a marker of proliferative granule cells (data not shown and Fig.4A). To determine the contribution of extrinsic cues to the differentiation process, we induced transgene expression in the presence or absence of stage specific extrinsic cues that had previously been shown to result in granule neuron differentiation from ES cells [12] (Growth Factors cocktail, Fig.5A). Very interestingly, expression of GABA $\alpha 6 \mathrm{r}$ and Zic1 was significantly 
enhanced by the transient induction of Mathl even in the presence of factors (Fig.5B). However, colabeling of cells with Tuj1 and MAP2 revealed that the vast majority of the Tuj1-expressing neurons were also positive for the mature neuronal marker MAP2 when factors were added (92\%) as compared to basal conditions (58\%) irrespective of Math1 induction (Fig.5C). Therefore, while Math1 activates subtype specific markers, it is not sufficient for pan-neuronal differentiation and maturation. Moreover, cell counting showed that the number of neurons that expressed GABA $\alpha 6 \mathrm{r}$ was maximal when Math1 was induced in the presence of factors (66\% versus Tuj1 and $73 \%$ versus MAP2, Fig.5C). The number of Tuj1-neurons that expressed Zic1 was also significantly increased when Math1 induction and extrinsic factors were combined (86\%) as compared to all other conditions (Fig.5C). A similar trend was observed with Pde1c (Supporting Information Fig.3B). These increases were not due to a greater number of neurons since Math1 activation in the presence of factors had no effect on Tuj1 expression and did not change the number of Tuj 1 positive cells that expressed MAP2 (Fig.5C and Supporting Information Fig.3A). By contrast, the number of cells that expressed markers of non-granule fate like serotonin (5-HT) and tyrosine hydroxylase (TH) was significantly decreased by the combined action of Math1 and factors. Similarly, no effect was seen on MyosinVIIa (Fig.6B), a marker of mature sensory hair cells, which require Math1 expression outside the nervous system [21]. Similar data were obtained with the two other clones (Supporting Information Fig. 6 and not shown). Together, these data indicate that maturation of granule neurons requires extrinsic signals and that the combined action of Mathl transient expression and extrinsic factors has a stronger effect on the specific stimulation of granule neurons markers than that triggered by either Mathl expression or factors addition.

\section{Expression of granule cell markers is coincident with mature granule neuron morphology and functional neurons}

We examined the morphology of the differentiated cultures and performed electrophysiological measurements in vitro. In order to demonstrate functionality we recorded in the condition that gave the maximum percentage of neurons positive for GABA $\alpha 6 \mathrm{r}$ and Zic1 (Fig.6A). In these clone 1.2 cultures the majority of the neurons harbored a small ovoid cell body with a T-shaped axon, a signature of differentiated granule cells, established synapses and expressed synaptophysin (Fig.6A). These cells were recorded in current clamp mode to assess whether they were able to generate action potential. We first investigated if at resting potential these cells were able to generate spontaneous action potential and then if they were able to generate firing of action potentials under sustained controlled depolarization. Two categories of cells were visually selected. The first type presented long T-shaped processes and ovoid cell body, typical of granule cells. The 
second type presented only short processes and large cell body. Action potentials were never recorded in patched cells of this phenotype. By contrast, spontaneous action potentials as well as sustained firing under controlled depolarization were systematically recorded in the first type of cells $(\mathrm{n}=8)$ (Fig.6C). Similar results were obtained with clone 1.3 and clone 2.8 (Supporting Information Fig.6). This suggests that the differentiated granule neurons were indeed functional neurons capable of generating action potentials.

To determine whether the newly generated neurons could also integrate in the cerebellum in vivo, we implanted Dox-induced clone 1.2-derived progenitors at NS stage into the cerebellum of young adult mice (P60) and tracked down the cells in sagittal cerebellar sections one week after implantation. In all mice processed $(n=5)$, DsRed-postive cells could be detected in cerebellar lobules close to the injection site, mainly in the molecular layer (Fig.7A). Co-labeling with an antiTuj1 antibody showed that many of the DsRed-positive cells strongly expressed Tuj1 (Fig.7B), displayed a neuronal shape and started to colonize the granule cell layer (Fig.7C-D). A few implanted neurons located in the granule cell layer were found positive for the GABA $\alpha 6$ receptor (Fig.7E-F).

Taken together, these data suggest that Dox-induced progenitors can give rise to functional neurons in vitro and in vivo.

\section{DISCUSSION}

The data presented in this study indicate that conditional induction of Mathl is sufficient to drive ES cells into granule neuron lineage, that extrinsic signals are required for granule neuron maturation and that the combination of Mathl temporally-controlled expression with these extrinsic cues efficiently increases the proportion of mature cerebellar granule neurons. Given the importance of developing in vitro models of development of specific neuronal types, it is critical to understand how cell intrinsic and extrinsic cues interact with each other to specify neuronal subtype in vitro. We have delineated the contribution of Math1 as a cell intrinsic determinant of subtype identity in directing ES differentiation into neurons versus the requirement of other extrinsic cues and parallel signaling pathways in the specification of GNPs. The question is important because specification of granule neurons and their proliferation and differentiation are spatially and temporally separated.

Over-expression and deletion studies have shown that correct levels of Math1 are required for granule neuron differentiation making it obligatory to use an inducible system $[8,22]$. Using an inducible system, we were able to determine that the most appropriate window for Math1 transient 
expression corresponded to the EBs stage that mimics signaling centers [6]. Our first major finding is that transient expression of Math1 in the absence of more specific cues for cerebellar patterning is sufficient to induce markers of granule neurons during RA-induced differentiation of ES cells into neurons. Our second major result is the increased efficiency of reprogramming when we use transient gene expression system along with extrinsic cues. We have shown here that combining a temporally controlled expression of Math1 along with extrinsic signals leads to $73 \%$ of neurons acquiring a granule fate. This approach has recently brought encouraging results when trying to derive difficult to get neuronal subtypes such as was shown with serotonin [23-24, 25].

In terms of how closely ES cell differentiation follows what happens in vivo, we firstly show that transient induction of Mathl is enough for the persistent activation of the downstream target genes $M b h 1$ and $M b h 2$ that are essential for granule neuron specification [20]. Increase in $M b h 1$ and $M b h 2$ in turn led to an increase in its downstream target TAG1 showing the sustained downstream activation of GNPs specification pathway by transient Math1 induction. Thus, we saw increased expression of TAG1 as well as Pde1c, a specific marker for the granule neuron lineage while sensory hair cells markers like Myosin VIIa were not favored in our system.

NeuroD and Pax6 are two other downstream targets of Math1 [26]. Previous studies have suggested that NeuroD is an early marker for neuronal differentiation [27, 28]. Our result showing increased NeuroD at early stages but not at later stages of granule cell differentiation is consistent with the fact that downstream targets are activated in the correct temporal sequence by transient Math1 induction. Pax6 like En1 is expressed in the RL from which Math1 positive cells are generated [20, 29] and in addition, Pax6 is expressed at low levels in proliferating granule neurons and higher levels in differentiating cells [30]. Consistent with this, our results also show an expression of Pax6 maintained throughout differentiation.

Proneural genes activate neural versus glial differentiation program and in this context Math1 has been shown to not only induce the expression of downstream genes that are important in granule neuron specification but is also thought to increase the expression of Tuj1 through a parallel pathway [20, 31]. Math1 expression in ES cell differentiation recapitulated both aspects of proneural gene function by increasing the expression of pan neuronal and neuronal subtype specific marker. The increase in Tuj1 expression resulted in a decrease in GFAP labeled cells but not in a decrease of non-neuronal cells. This is consistent with studies that have shown that proneural genes including Mathl bias neuronal differentiation at the expense of glial differentiation [32, 33, 34].

Regulation of neuronal progenitor proliferation and cell cycle exit is an important component of the pan neuronal differentiation program. In our study we observed a slight but significant increase in cell proliferation at late EBs stage due to Math1 induction and subsequent up-regulation of Zic1. This is consistent with what has been seen in vivo where Mathl regulates the Notch 
pathway and in its absence there is decreased cell proliferation $[35,36]$ and $\mathrm{Zic} 1 / 2$ also plays a role in cell proliferation [37].

En1 marks the entire mesencephalon/rhombomere 1 territory $[38,39]$ and its expression is induced by extrinsic cues [40]. During development En1 is also co-expressed by Math1 positive granule neurons early in development but is not expressed by mature granule neurons of the inner granule layer. Interestingly, En1 was up-regulated even in the absence of extrinsic cues by Math1 induction. Furthermore this increased En1 expression was seen only at early and not at later stages as predicted from developmental data.

Zic1 and Zic2 are two transcription factors that are expressed in the RL and have overlapping patterns of development and cooperate in cerebellar development [41]. Like En1, we could induce Zic1 and Zic2 by transient expression of Math1 without the addition of extrinsic factors. This shows that even in the absence of extrinsic cues, Math1 activation is sufficient for induction of En1, Zic1 and Zic2 in the correct temporal sequence. However, Zic1 can also be induced by BMP6 and BMP7 [35] and it binds to the upstream region of Math1 to repress its transcription [40]. We found that even in the absence of Mathl induction, Zicl levels increased significantly upon factors addition. This goes along with the observation that Zic1 may be a parallel pathway involved in granule neuron proliferation which could be under the control of extrinsic factors and cross-talk with Math1 [35].

Mathl induction did not impact neuronal maturation as the number of neurons expressing MAP2 remained stable but resulted in a significant increase in the number of MAP2-positive neurons expressing GABA $\alpha 6$ r, a specific marker for mature granule neurons $(+16 \%)$. The temporal regulation of GABA $\alpha 6 \mathrm{r}$ is particularly interesting as its expression depends on very precise temporal dynamics of two transcription factors NF1 and REST [42]. The fact that we see an upregulation of GABA $\alpha 6 \mathrm{r}$ with Math1 induction in the absence of specific extrinsic cues suggests that this full program of neuronal maturation can occur in the absence of any specific extrinsic cues.

A recent study showed that several of Math1 target genes are those that are involved in extrinsic signals [26]. Extrinsic factors increased neuronal maturation and thus led to a 33\% increase in MAP2 positive and a significant increase in GABA $\alpha 6 \mathrm{r}$ in Tuj1 $(+35 \%)$ and MAP2 positive cells $(+15 \%)$. The net result of these two effects was that transient expression of Math1 along with extrinsic factors resulted in $73 \%$ of the MAP2 positive cells expressing the mature granule neuron marker GABA $\alpha 6 \mathrm{r}$ that is more than can be achieved by either condition alone $(+31.7 \%)$. Similarly, our data indicate that Pde1c is increased by either Math1 transient expression $(+19 \%)$ or extrinsic factors addition $(+15 \%)$, but that the combination of both effects results in even more Pdelcpositive neurons $(+31.7 \%$, Supporting Informations Fig. 3 and 6). Two studies have reported 
successful differentiation of mouse ES cells into cerebellar granule neurons [10, 12]. In the study by $\mathrm{Su}$ and colleagues, Math1-positive cerebellar progenitors were produced by the combination of rostral CNS induction and subsequent BMP4/Wnt3a treatment. With regard to the efficiency, yields of obtained granule progenitors have been provided based mainly on Zic1 expression (around 60\% of total cells) and therefore it is difficult to estimate the percentage yield of mature granule neurons. In the present study, combining Math1 transient expression with extrinsic factors generated $86 \%$ of Zic1-expressing neurons. Moreover, differentiation into granule cell lineage was achieved by using a coculture system in the presence of neonatal cerebellar granule neurons from mouse, and therefore the study was not intended to directly address the contribution of Math1 induction versus extrinsic cues. Similarly, in the study by Salero and Hatten, progenitors and mature cerebellar neurons were obtained in vitro using successive defined media that mimic the sequential differentiation steps of cerebellar differentiation in vivo. However, yields reported for final stage used differentiated neurons obtained with media conditioned by purified cerebellar granule neurons or glia.

In conclusion we were able to show that transient Math1 expression at EBs stage was enough to drive these cells into granule neuron lineage in the absence of other specific inducing factors that have been used previously. However, the addition of extrinsic cues activated other granule neuron specific genes with greater efficiency and increased neuronal maturation and thus overall led to an increase in granule neuron differentiation. This result thus identifies factors that will now help us to achieve even greater homogeneity of granule neuron subtype. In future more use of such a strategy should enable us to identify critical pathways that extrinsic cues induce to generate any kind of neuronal subtype in vitro and pave the way to advance our understanding of basic mechanisms of neuronal subtype specification and pathophysiological mechanisms underlying several neural diseases.

\section{ACKNOWLEDGMENTS}

We are grateful to Prof. Margaret Goodell, Baylor College of Medicine, Texas, for providing us the lentivirus pLTET-Luc, which was modified and used in the construction of cell line, to Sophie Lebon (INSERM U676, Paris, France) for her help and advice in molecular biology steps and to Cécile Martel for invaluable support. This study was supported by the Institut National pour la Santé et la Recherche Médicale (INSERM, France), the Centre National de la Recherche Scientifique (CNRS, France), Denis Diderot University (Paris7, France) and National Brain Research Centre (Haryana, India) and by grants from IFCPAR/CEFIPRA (project $\mathrm{N}^{\circ} 3803-3$ ), Department of Biotechnology (project $\mathrm{N}^{\circ} \mathrm{BT} / \mathrm{PR} 11653 / \mathrm{MED} / 31 / 602008$ ), French National Research Agency 
(project ANR-09-GENO-007), the Princesse Grâce de Monaco Foundation and the Roger de Spoelberch Foundation. SP was supported by grant from the Medical Research Council.

\section{REFERENCES}

1. Bai G, Pfaff SL. Protease Regulation: The Yin and Yang of Neural Development and Disease. Neuron 2011;72:9-21.

2. Kucherlapati R. Genetically Modified Mouse Models for Biomarker Discovery and Preclinical Drug Testing. Clin Cancer Res 2012;18:625-630.

3. Edlund T, Jessell TM. Progression from Extrinsic to Intrinsic Signaling in Cell Fate Specification: A View from the Nervous System. Cell 1999;96:211-224.

4. Jessell TM. Neuronal Specification in the Spinal Cord: Inductive Signals and Transcriptional Codes. Nat Rev Genet 2000;1:20-29.

5. Wurst W, Bally-Cuif L. Neural Plate Patterning: Upstream and Downstream of the Isthmic Organizer. Nat Rev Neurosci 2001;2:99-108.

6. Peljto M, Wichterle H. Programming Embryonic Stem Cells to Neuronal Subtypes. Curr Opin Neurobiol 2011;21:43-51.

7. Hatten ME, Heintz N. Mechanisms of Neural Patterning and Specification in the Developing Cerebellum. Annu Rev Neurosci 1995;18:385-408.

8. Ben-Arie N, Bellen HJ, Armstrong DL, et al. Math1 Is Essential for Genesis of Cerebellar Granule Neurons. Nature 1997;390:169-172.

9. Chedotal A. Should I Stay or Should I Go? Becoming a Granule Cell. Trends Neurosci 2010;33:163-172.

10. Su HL, Muguruma K, Matsuo-Takasaki M, et al. Generation of Cerebellar Neuron Precursors from Embryonic Stem Cells. Dev Biol 2006;290:287-296.

11. Erceg S, Ronaghi M, Zipancic I, et al. Efficient Differentiation of Human Embryonic Stem Cells into Functional Cerebellar-Like Cells. Stem Cells Dev 2010;19:1745-1756.

12. Salero E, Hatten ME. Differentiation of Es Cells into Cerebellar Neurons. Proc Natl Acad Sci U S A 2007;104:2997-3002.

13. Vieyra DS, Goodell MA. Pluripotentiality and Conditional Transgene Regulation in Human Embryonic Stem Cells Expressing Insulated Tetracycline-on Transactivator. Stem Cells 2007;25:2559-2566.

14. Lee SH, Lumelsky N, Studer L, et al. Efficient Generation of Midbrain and Hindbrain Neurons from Mouse Embryonic Stem Cells. Nat Biotechnol 2000;18:675-679.

15. Schmittgen TD, Livak KJ. Analyzing Real-Time Pcr Data by the Comparative C(T) Method. Nat Protoc 2008;3:1101-1108.

16. Bradford MM. A Rapid and Sensitive Method for the Quantitation of Microgram Quantities of Protein Utilizing the Principle of Protein-Dye Binding. Anal Biochem 1976;72:248-254.

17. Anderson WW, Collingridge GL. The Ltp Program: A Data Acquisition Program for onLine Analysis of Long-Term Potentiation and Other Synaptic Events. J Neurosci Methods 2001;108:71-83.

18. Anderson WW, Collingridge GL. Capabilities of the Winltp Data Acquisition Program Extending Beyond Basic Ltp Experimental Functions. J Neurosci Methods 2007;162:346356.

19. Saba R, Johnson JE, Saito T. Commissural Neuron Identity Is Specified by a Homeodomain Protein, Mbh1, That Is Directly Downstream of Math1. Development 2005;132:2147-2155.

20. Kawauchi D, Saito T. Transcriptional Cascade from Math1 to Mbh1 and Mbh2 Is Required for Cerebellar Granule Cell Differentiation. Dev Biol 2008;322:345-354. 
21. Bermingham NA, Hassan BA, Price SD, et al. Math1: An Essential Gene for the Generation of Inner Ear Hair Cells. Science 1999;284:1837-1841.

22. Helms AW, Gowan K, Abney A, et al. Overexpression of Math1 Disrupts the Coordination of Neural Differentiation in Cerebellum Development. Mol Cell Neurosci 2001;17:671-682.

23. Kumar M, Kaushalya SK, Gressens P, et al. Optimized Derivation and Functional Characterization of 5-Ht Neurons from Human Embryonic Stem Cells. Stem Cells Dev 2009;18:615-627.

24. Nefzger CM, Haynes JM, Pouton CW. Directed Expression of Gata2, Mash1, and Foxa2 Synergize to Induce the Serotonergic Neuron Phenotype During in Vitro Differentiation of Embryonic Stem Cells. Stem Cells 2011;29:928-939.

25. Dolmazon V, Alenina N, Markossian S, et al. Forced Expression of Lim Homeodomain Transcription Factor 1b Enhances Differentiation of Mouse Embryonic Stem Cells into Serotonergic Neurons. Stem Cells Dev 2011;20:301-311.

26. Klisch TJ, Xi Y, Flora A, et al. In Vivo Atoh1 Targetome Reveals How a Proneural Transcription Factor Regulates Cerebellar Development. Proc Natl Acad Sci U S A 2011;108:3288-3293.

27. Lee JK, Cho JH, Hwang WS, et al. Expression of Neurod/Beta2 in Mitotic and Postmitotic Neuronal Cells During the Development of Nervous System. Dev Dyn 2000;217:361-367.

28. Pan N, Jahan I, Lee JE, et al. Defects in the Cerebella of Conditional Neurod1 Null Mice Correlate with Effective $\operatorname{Tg}$ (Atoh1-Cre) Recombination and Granule Cell Requirements for Neurod1 for Differentiation. Cell Tissue Res 2009;337:407-428.

29. Engelkamp D, Rashbass P, Seawright A, et al. Role of Pax6 in Development of the Cerebellar System. Development 1999;126:3585-3596.

30. Flora A, Klisch TJ, Schuster G, et al. Deletion of Atoh1 Disrupts Sonic Hedgehog Signaling in the Developing Cerebellum and Prevents Medulloblastoma. Science 2009;326:1424-1427.

31. Bertrand N, Castro DS, Guillemot F. Proneural Genes and the Specification of Neural Cell Types. Nat Rev Neurosci 2002;3:517-530.

32. Sun Y, Nadal-Vicens M, Misono S, et al. Neurogenin Promotes Neurogenesis and Inhibits Glial Differentiation by Independent Mechanisms. Cell 2001;104:365-376.

33. Nakamichi N, Ishioka Y, Hirai T, et al. Possible Promotion of Neuronal Differentiation in Fetal Rat Brain Neural Progenitor Cells after Sustained Exposure to Static Magnetism. J Neurosci Res 2009;87:2406-2417.

34. Gu F, Hata R, Ma YJ, et al. Suppression of Stat3 Promotes Neurogenesis in Cultured Neural Stem Cells. J Neurosci Res 2005;81:163-171.

35. Gazit R, Krizhanovsky V, Ben-Arie N. Math1 Controls Cerebellar Granule Cell Differentiation by Regulating Multiple Components of the Notch Signaling Pathway. Development 2004;131:903-913.

36. Weller M, Krautler N, Mantei N, et al. Jagged1 Ablation Results in Cerebellar Granule Cell Migration Defects and Depletion of Bergmann Glia. Dev Neurosci 2006;28:70-80.

37. Behesti H, Marino S. Cerebellar Granule Cells: Insights into Proliferation, Differentiation, and Role in Medulloblastoma Pathogenesis. Int J Biochem Cell Biol 2009;41:435-445.

38. Zervas M, Millet S, Ahn S, et al. Cell Behaviors and Genetic Lineages of the Mesencephalon and Rhombomere 1. Neuron 2004;43:345-357.

39. Machold R, Fishell G. Math1 Is Expressed in Temporally Discrete Pools of Cerebellar Rhombic-Lip Neural Progenitors. Neuron 2005;48:17-24.

40. Roussel MF, Hatten ME. Cerebellum Development and Medulloblastoma. Curr Top Dev Biol 2011;94:235-282.

41. Aruga J, Inoue T, Hoshino J, et al. Zic2 Controls Cerebellar Development in Cooperation with Zic1. J Neurosci 2002;22:218-225.

42. Wang W, Shin Y, Shi M, et al. Temporal Control of a Dendritogenesis-Linked Gene Via Rest-Dependent Regulation of Nuclear Factor I Occupancy. Mol Biol Cell 2011;22:868-879. 


\begin{tabular}{|c|c|c|c|}
\hline Primer & Sequence forward/reverse $\left(5^{\prime}-3^{\prime}\right)$ & $\begin{array}{l}\text { Amplicon } \\
\text { size (bp) }\end{array}$ & $\begin{array}{l}\text { Annealing } \\
\text { temp }\left({ }^{\circ} \mathrm{C}\right)\end{array}$ \\
\hline BMP2 & $\begin{array}{l}\text { GGGACCCGCTGTCTTCTAGT / } \\
\text { TCAACTCAAATTCGCTGAGGAC }\end{array}$ & 154 & 60 \\
\hline En1 & $\begin{array}{l}\text { CGGTGGTCAAGACTGACTC / } \\
\text { TAGCTTCCTGGTGCGTGGA }\end{array}$ & 104 & 60 \\
\hline GABAa6r & $\begin{array}{l}\text { GTCAGTCGGATTCTTGACAACT / } \\
\text { GGTCCAAAGCTGGTCACATAG }\end{array}$ & 113 & 62 \\
\hline GATA4 & $\begin{array}{l}\text { TGATAGAGGCCACAGGCATT / } \\
\text { CTGGAAGACACCCCAATCTC }\end{array}$ & 139 & 60 \\
\hline GFAP & $\begin{array}{l}\text { GGGACAACTTTGCACAGGAC / } \\
\text { GCTTCATCTGCCTCCTGTCT }\end{array}$ & 115 & 60 \\
\hline HPRT & $\begin{array}{l}\text { GGTGAAAAGGACCTCTCGAA / } \\
\text { CAAGGGCATATCCAACAACA }\end{array}$ & 89 & $60 / 62$ \\
\hline Ki67 & $\begin{array}{l}\text { CCTGCCTGTTTGGAAGGAGT / } \\
\text { ATTGCCTCTTGCTCTTTGACT }\end{array}$ & 101 & 60 \\
\hline MAP2 & $\begin{array}{l}\text { GCTGGCAAGAATTAAGGTTCC / } \\
\text { TGGTGGTATGTTCTGGCTTCT }\end{array}$ & 105 & 60 \\
\hline Math1 & $\begin{array}{l}\text { GAGTGGGCTGAGGTAAAAGAGT / } \\
\text { GGTCGGTGCTATCCAGGAG }\end{array}$ & 151 & 60 \\
\hline Mbh1 & $\begin{array}{l}\text { CATCAAATGCCACGGAACAA / } \\
\text { AGCTGGTGGTCTGAGAAAGC }\end{array}$ & 120 & 60 \\
\hline Mbh2 & $\begin{array}{l}\text { GAACCGCAGGACTAAATGGA / } \\
\text { AGAAATAAGGCGACGGGAAC }\end{array}$ & 107 & 60 \\
\hline Myosin VIIa & $\begin{array}{l}\text { CAGAATGCCACGCACATCAAG / } \\
\text { TGGTCCCGGTAGCGAATGA }\end{array}$ & 126 & 62 \\
\hline Nestin & $\begin{array}{l}\text { CCCTGAAGTCGAGGAGCTG / } \\
\text { CTGCTGCACCTCTAAGCGA }\end{array}$ & 166 & 60 \\
\hline NeuroD1 & $\begin{array}{l}\text { ACGCAGAAGGCAAGGTGTC / } \\
\text { CGCTCTCGCTGTATGATTTG }\end{array}$ & 108 & 60 \\
\hline Olig2 & $\begin{array}{l}\text { TCACATTCGGAAGGTTGAAAA / } \\
\text { GACGATGGGCGACTAGACA }\end{array}$ & 101 & 60 \\
\hline Pax6 & $\begin{array}{l}\text { GTTGGTGTGTTCCCTGTCC / } \\
\text { TACGGGGCTCTGAGAACTG }\end{array}$ & 133 & 60 \\
\hline Pde1c & $\begin{array}{l}\text { GATGGTACAAAGAAGCGTTCTCA / } \\
\text { CAAGGTAATGCGACTTGTGGA }\end{array}$ & 69 & 62 \\
\hline TAG1 & $\begin{array}{l}\text { GAATCCGCACTAAGGAAGCA / } \\
\text { TGACATGGGAGTCCAGTTGA }\end{array}$ & 101 & 60 \\
\hline Tuj1 & $\begin{array}{l}\text { TGGACAGTGTTCGGTCTGG / } \\
\text { CCTCCGTATAGTGCCCTTTGG }\end{array}$ & 108 & 60 \\
\hline Zic1 & $\begin{array}{l}\text { AAGGACACACACAGGGGAGA / } \\
\text { TTGCAAAGGTAGGGCTTGTC }\end{array}$ & 126 & 60 \\
\hline Zic2 & $\begin{array}{l}\text { GCAAGATGTGTGACAAGTCC / } \\
\text { TGGACGACTCGTAGCCAGA }\end{array}$ & 123 & 60 \\
\hline
\end{tabular}

Srivastava et al, Table 1: Primers and annealing temperatures used for real time PCR 


\begin{tabular}{|c|c|c|c|}
\hline Antibody & Company & Catalogue & Dilution \\
\hline \multicolumn{4}{|l|}{ Primary } \\
\hline BarH1/Mbh2 & Millipore & AB5943 & $1: 300$ \\
\hline BarH2/Mbh1 & ABcam & $\mathrm{ab82639}$ & $1: 50$ \\
\hline Cleaved Caspase 3 & Cell Signaling & $9661 \mathrm{~L}$ & $1: 200$ \\
\hline DsRed & Clontech & 632496 & $1: 200$ \\
\hline En1 & Millipore & AB5732 & $1: 200$ \\
\hline GABA A receptor $\alpha 6$ & Millipore & AB5610 & $1: 500$ \\
\hline GFAP & Sigma & G 3893 & $1: 400$ \\
\hline Ki67 & BD Pharmingen & 556003 & $1: 250$ \\
\hline MAP2 & ABcam & $\mathrm{ab1} 1268$ & $1: 400$ \\
\hline Math1 & Acris & AP00308PU-N & $1: 200$ \\
\hline Myosin VIIa & ABcam & ab3481 & $1: 500$ \\
\hline Nestin & Millipore & MAB353 & $1: 200$ \\
\hline Oct4 & Millipore & MAB4419 & $1: 200$ \\
\hline Olig2 & Millipore & AB9610 & $1: 200$ \\
\hline Pax6 & ABcam & ab5790 & $1: 200$ \\
\hline Pde1c & ABcam & ab14602 & $1: 150$ \\
\hline Serotonin & Sigma & S5545 & $1: 200$ \\
\hline SSEA1 & DSHB & MC-480 & $1: 500$ \\
\hline Synaptophysin & Sigma & S5768 & $1: 200$ \\
\hline Tuj1 & Covance & MMS-435P & $1: 1000$ \\
\hline Tuj1 & Covance & PRB-435P & $1: 1000$ \\
\hline Tyrosine hydroxylase & Covance & PRB-515P & $1: 500$ \\
\hline Zic1 & ABcam & $\mathrm{ab72694}$ & $1: 200$ \\
\hline Zic2 & ABcam & $\mathrm{ab} 12072$ & $1: 200$ \\
\hline \multicolumn{4}{|l|}{ Secondary } \\
\hline Donkey Anti-Mouse IgG (AF 488) & Invitrogen & A-21202 & $1: 1000$ \\
\hline Donkey Anti-Mouse IgG (AF594) & Invirogen & A-21203 & $1: 1000$ \\
\hline Donkey Anti-Rabbit IgG (AF488) & Invitrogen & A-21206 & $1: 1000$ \\
\hline Donkey Anti-Rabbit IgG (AF594) & Invitrogen & A-21207 & $1: 1000$ \\
\hline Goat Anti-Mouse IgG (AF488) & Invitrogen & A-11029 & $1: 1000$ \\
\hline Goat Anti-Mouse IgG (AF594) & Invitrogen & A-11032 & $1: 1000$ \\
\hline Goat Anti-Mouse IgM (AF594) & Invitrogen & A-21044 & $1: 1000$ \\
\hline Goat Anti-Rabbit IgG (AF488) & Invitrogen & A-11008 & $1: 1000$ \\
\hline Goat Anti-Rabbit IgG (AF594) & Invitrogen & A-11012 & $1: 1000$ \\
\hline
\end{tabular}

Srivastava et al, Table 2: Antibodies and dilutions used for immunocytochemistry 


\section{FIGURE LEGENDS}

\section{Figure 1. Generation of the Math1-inducible ES cell lines using the Tet-On system.}

(A): Sketch of the vectors used to generate the cell lines which conditionally express Math1 upon doxycycline (Dox) exposure by modification of ESD3 cells. Upon Dox addition, the transactivator rtTA2s-M2 encoded by the modified pTet-On Advanced regulator plasmid binds the TRE-T promoter and triggers the expression of Math1. (B): Overview of the 31-day experimental protocol of neuronal differentiation (basal condition) of Mathl-inducible ES cells (UD: Undifferentiated, EBs: Embryonic bodies, NS: Neurospheres, FD: Final differentiation, RA: Retinoic Acid). (C): Classic PCR analyses of Mathl gene expression at all stages of differentiation, upon two days Dox addition and removal (induction for A at UD, for B at early EBs, for C at late EBs, for D at NS and for E at FD stage). Dox reversibly activates Math1 expression at all stage of differentiation. (D): Real time PCR analyses of Mathl gene expression at all stages of differentiation, upon two days Dox addition and removal. Dox activates Math1 expression with a higher efficiency when added at early or late EBs stages. (E, F): Immunocytochemistry and western blot analysis of Math1 expression upon Dox addition during (early+late) EBs stage. Control tissue samples for Math1 expression were dissected out from P4 mice cerebella $(\mathrm{P} 4 \mathrm{cb})$. Scale bar $=50 \mu \mathrm{m}$.

Figure 2. Activation of Mbh1 and Mbh2 following Dox-induced Math1 overexpression at EBs. (A): Real-time PCR analysis of Mbhl and Mbh2 genes expression after Math1 induction at the different stages of differentiation. The analysis was done on the cell pellets collected at the end of final stage for all the conditions. Mbh1 and Mbh2 expression is higher when Math1 is induced at early or late EB stage. (B): Real-time PCR analysis of $M b h 1$ and $M b h 2$ gene expression 3, 7, 17 and 31 days after initiation of Math1 induction at EB stage. When Math1 is induced at (early+late) EB stage, activation of $M b h 1$ and $M b h 2$ is persistently detected over time. (C): Immunocytochemistry detection of Mbh1 and Mbh2 proteins in Nestin-expressing cells at NS stage with (Dox) and without (Ctl) Math1 induction at EB stage. Both proteins are more abundantly detected after Math1 induction. Scale bar $=50 \mu \mathrm{m}$.

Figure 3. Analysis of neural differentiation markers following Dox-induced Math1 transient expression at EBs.

(A): Real-time PCR analysis of Tuj1, GFAP, MAP2 and Olig2 genes expression at FD stage with (Dox) and without (Ctl) Mathl induction. Quantitative data are expressed as mean $\pm \mathrm{SEM}$ for each group. Statistical analyses show significant differences for all markers $(\mathrm{n}=11$, Tuj $1 * \mathrm{P}=0.0286$, GFAP *** $\mathrm{P}=0.0006, \mathrm{MAP} 2 * \mathrm{P}=0.0488$, Olig2 * $\mathrm{P}=0.0278$ (Mann-Whitney)). (B): Cell countings 
of Tuj1, GFAP, MAP2 and Olig2 after immunocytochemistry at FD stage in Ctl and Dox cultures. Cells positive for Tuj1 and MAP2 are more numerous upon Dox addition and cells positive for GFAP are less. Quantitative data are expressed as mean \pm SEM for each group $(n=6$, Tuj1 *** $\mathrm{P}=0.0002$, GFAP and MAP2 ** $\mathrm{P}=0.0022$ (Mann-Whitney)). Analysis of cell distribution shows that Tuj1 is increased and GFAP decreased under Dox conditions while the total number of neural cells (Olig2+GFAP+Tuj1) remains stable in both conditions. (C): Representative immunolabelings at FD stage of Tuj1, GFAP, MAP2 and Olig2 in Ctl and Dox cultures. Scale bar $=50 \mu \mathrm{m}$.

Figure 4. Analysis of cerebellar granule cell markers following Dox-induced Math1 transient expression at EBs.

(A): Real-time PCR analysis of cerebellar granule cell markers at FD stage with (Dox) and without (Ctl) Math1 induction. Quantitative data are expressed as mean \pm SEM for each group. ( $\mathrm{n}=11$, GABAa6r ** $\mathrm{P}=0.0052$, TAG1 * $\mathrm{P}=0.0255$, Zic1 ** $\mathrm{P}=0.0166$, Pde1c * $\mathrm{P}=0.0356$, (MannWhitney)). (B): Cell countings of cerebellar granule cell markers after immunocytochemistry at FD stage in $\mathrm{Ctl}$ and Dox cultures. Quantitative data are expressed as mean \pm SEM for each group. ( $\mathrm{n}=6$, GABAa6r vs MAP2 ** $\mathrm{P}=0.0022$, Zic1 ** $\mathrm{P}=0.0022$, Zic2 * $\mathrm{P}=0.026$, Pde1c ** $\mathrm{P}=0.005$ (MannWhitney)). (C): Representative immunolabelings at FD stage of cerebellar granule cell markers in $\mathrm{Ctl}$ and Dox cultures. Scale bar $=50 \mu \mathrm{m}$.

Figure 5. Analysis of cerebellar granule cell markers following combined Dox-induced Math1 transient expression and extrinsic factors addition.

(A): Overview of the 31-day experimental protocol for cerebellar differentiation of the Math1inducible ES cell line (Basal condition+Growth Factor Cocktail). (B): Real-time PCR analysis of GABAa6r and Zic1 genes expression at FD stage in the presence or absence of extrinsic factors (GF cocktail) in Ctl and Dox cultures. Quantitative data are expressed as mean $\pm \mathrm{SEM}$ for each group. ( $\mathrm{n}=11$, GABA $\alpha 6 \mathrm{r}$ basal conditions ** $\mathrm{P}=0.0052$, GABA $\alpha 6 \mathrm{r}$ basal conditions $+\mathrm{GF}$ cocktail ** $\mathrm{P}=0.0022$, effect of extrinsic factors (GF cocktail) on GABA $\alpha 6 \mathrm{r}$ in induced cells \#\#\# $\mathrm{P}=0.0001$. $\mathrm{n}=11$, Zic1 basal conditions $* \mathrm{P}=0.0166$, Zic1 basal conditions $+\mathrm{GF}$ cocktail $* * \mathrm{P}=0.0017$, effect of extrinsic factors (GF cocktail) on Zic1 in induced cells \#\#\# P=0.0002 (Mann-Whitney)). (C): Cell countings of cerebellar granule cell markers after immunocytochemistry at FD stage in the presence or absence of extrinsic factors (GF cocktail) in $\mathrm{Ctl}$ and Dox cultures. Quantitative data are expressed as mean $\pm \mathrm{SEM}$ for each group. $(\mathrm{n}=6, * * \mathrm{P}=0.0022$, \#\# $\mathrm{P}=0.022$. (Mann-Whitney)). 
Figure 6. Immunocytochemistry and electrophysiological analyses of mature cerebellar granule neurons following combined Dox-induced Math1 transient expression and extrinsic factors addition.

(A): Representative immuno-colabelings at FD stage of cerebellar granule cell markers in Doxinduced cultures with extrinsic factors (GF cocktail). A majority of Tuj1- or MAP2-expressing cells also express GABAa6r (a, b), Zic1 (e) and Zic2 (f). Scale bar $=10 \mu \mathrm{m}$. Mature neurons show Neurofilament (NF-M)-positive T-shaped axons $(\mathrm{g}, \mathrm{h})$ resembling axons from primary cultured granule neurons (d), establish synapses and express Synaptophysin (SYN) (c). (B): Cell countings of mature neurons positive for serotonin (5-HT) or Tyrosine Hydroxylase (TH) and of cells positive for Myosin VIIa (MyosVIIa) at FD stage in the presence of extrinsic factors (GF cocktail) in noninduced (Ctl) and Math1-induced cultures (Dox). Quantitative data are expressed as mean $\pm \mathrm{SEM}$ for each group. $(\mathrm{n}=6, * * \mathrm{P}=0.0022$, (Mann-Whitney)). (C): Mature neurons are able to generate spontaneous action potentials (from top to bottom: short spontaneous sustained firing, spontaneous activity and firing following $30 \mathrm{mV}$ depolarization).

\section{Figure 7. Intracerebellar implantation of Dox-induced cl 1.2-derived progenitors}

(A-D): Co-staining of the cerebellar sections using anti-Tuj1 (green) and anti-DsRed (red) antibodies to track the implanted cells and determine their neuronal differentiation potential in vivo. $\mathrm{B}$ is an orthogonal viewing of the double staining allowing a simultaneous viewing of the XY image along with a cross section and indicating colocalization areas of Tuj1 and DsRed. (scale bars: 1mm in $\mathrm{A}, 50 \mu \mathrm{m}$ in B and C, $10 \mu \mathrm{m}$ in D) (E-F): Co-staining of the cerebellar sections using anti-Tuj1 (red) and anti-GABA $\alpha 6 \mathrm{r}$ (green). The implanted cells strongly express Tuj1 and some of these cells also express the GABA $\alpha 6$ receptor (white arrows). (scale bars: $50 \mu \mathrm{m}$ in E, $10 \mu \mathrm{m}$ in F).

\section{Supporting Information Figure 1.}

Sustained expression of the pluripotency-related markers SSEA1 and Oct4 in control ESD3 cells and Math1-inducible clone 1.2. Scale bar $=20 \mu \mathrm{m}$.

\section{Supporting Information Figure 2.}

(A): RT-PCR of markers of the three germ layers (endoderm (GATA4), mesoderm (Bmp2) and neurectoderm (Nestin, Pax6) in early EBs (before RA addition) and late EBs (RA-induced). Note that expression of both Nestin and Pax6 is strongly increased upon RA induction. 
(B): Real-time PCR analysis of En1 and NeuroD1 in late EBs and FD stage with (Dox) and without (Ctl) Math1 induction. Quantitative data are expressed as mean \pm SEM for each group. (late EBs: $\mathrm{n}=11$, En1 *** $\mathrm{P}<0.0001$, NeuroD1 * $\mathrm{P}=0.0374$. FD stage: $\mathrm{n}=11$, En1 *** $\mathrm{P}=0.0013$, NeuroD1 $\mathrm{P}=0.3403$ (Mann-Whitney)). (C): Cell countings of Ki67 and cleaved caspase3 in late EBs and Neurospheres (NS) in $\mathrm{Ctl}$ and Dox cultures. Quantitative data are expressed as mean $\pm \mathrm{SEM}$ for each group. ( $\mathrm{n}=6, * * \mathrm{P}=0.0022$, (Mann-Whitney)).

\section{Supporting Information Figure 3.}

(A): Real-time PCR analysis of Tuj1, GFAP, MAP2 and Olig2 genes expression at FD stage in the presence of extrinsic factors (GF cocktail) with (Dox) and without (Ctl) Math1 induction. Quantitative data are expressed as mean \pm SEM for each group. (B): Cell countings of En1, Zic2 and Pde1c at FD stage in the presence or absence of extrinsic factors (GF cocktail) in Ctl and Dox cultures. Quantitative data are expressed as mean \pm SEM for each group. ( $\mathrm{n}=6$, En1 ** $\mathrm{P}=0.0022$, \#\# $\mathrm{P}=0.022$. Zic2 vs Tuj1 without factors * $\mathrm{P}=0.0260$, Pde1c ** $\mathrm{P}=0.005$ and $\# \# \mathrm{P}=0.022$ (MannWhitney)).

\section{Supporting Information Figure 4. Neural properties of clone 1.2 and comparison with ESD3 and ESB6 cell lines.}

(A): Cell countings of Tuj1, GFAP, MAP2 and Olig2 at FD stage in basal conditions for the three cell lines clone 1.2, ESD3 and ESB6. Quantitative data are expressed as mean $\pm \mathrm{SEM}$ for each group (n=6). (B): Representative immunolabelings of Tuj1, MAP2, GFAP and Olig2 at FD stage in basal conditions for the three cell lines. Scale bar $=50 \mu \mathrm{m}$

\section{Supporting Information Figure 5.}

(A): Real time PCR and western blot analysis of Math1 expression upon Dox addition of clones 1.3 and 2.8 during (early+late) EBs stage (B): Cell countings of Tuj1, GFAP, MAP2 and Olig2 after immunocytochemistry at FD stage in Ctl and Dox cultures from clones 1.3 and 2.8. Like in clone 1.2, cells positive for Tuj1 and MAP2 are more numerous upon Dox addition and cells positive for GFAP are less. Quantitative data are expressed as mean \pm SEM for each group $(n=6$, clone 1.3,** $\mathrm{P}=0.0022, \mathrm{n}=6$, clone $2.8 * * \mathrm{P}=0.0022$ (Mann-Whitney)). (C): Representative immunolabelings at FD stage of Tuj1, MAP2, GFAP and Olig2 in Ctl and Dox cultures from clones 1.3 and 2.8. Scale bar $=50 \mu \mathrm{m}$.

\section{Supporting Information Figure 6.}


(A): Cell countings of cerebellar granule cell markers after immunocytochemistry at FD stage in the presence or absence of extrinsic factors (GF cocktail) in Ctl and Dox cultures from clones 1.3 and 2.8. Similar trends as described for clone 1.2 are observed. Quantitative data are expressed as mean \pm SEM for each group. (clone 1.3, $\mathrm{n}=6$, GABA $\alpha 6 \mathrm{r} * \mathrm{P}=0.0161, * * \mathrm{P}=0.005$, \#\# $\mathrm{P}=0.005$, Zic1 * $\mathrm{P}=0.0129, * * \mathrm{P}=0.0022$, $\mathrm{Pde} 1 \mathrm{c} * * \mathrm{P}=0.005$ in basal conditions, ** $\mathrm{P}=0.0022$ in the presence of GF cocktail, \#\# $\mathrm{P}=0.005$, MAP2 \#\# $\mathrm{P}=0.0022$ (Mann-Whitney) and clone 2.8, $\mathrm{n}=6$, GABA $\alpha 6 \mathrm{r}$ and Zic1, ** $\mathrm{P}=0.0022$, \#\# $\mathrm{P}=0.005$, Pde1c * $\mathrm{P}=0.0161$, ** $\mathrm{P}=0.0087$, \#\# $\mathrm{P}=0.0022$, MAP2 \#\# $\mathrm{P}=0.0022$ (Mann-Whitney)). (B): Representative immuno-colabelings at FD stage of cerebellar granule cell markers in Dox-induced cultures with extrinsic factors (GF cocktail). As shown for clone 1.2, in clone 1.3 and clone 2.8 derived cultures a majority of Tuj1- or MAP2-expressing cells also express GABAa6r, Zic1 and Pde1c. (C): Mature neurons are able to generate spontaneous activity (upper graph, cl 1.3) and firing following $30 \mathrm{mV}$ depolarization (middle and lower graphs, cl 1.3 and 2.8 respectively).

\section{Supporting Information Figure 7.}

Specificity of the immunostainings was checked using non-relevant primary antibodies that do not react with any antigen (mouse IgG1 isotype control (Abcam, ab126026) and rabbit IgG isotype control (Abcam, ab27478). 
A

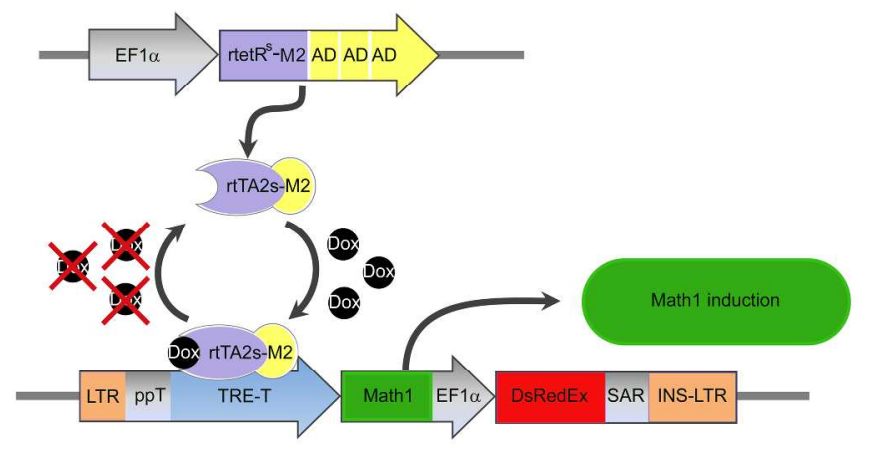

B

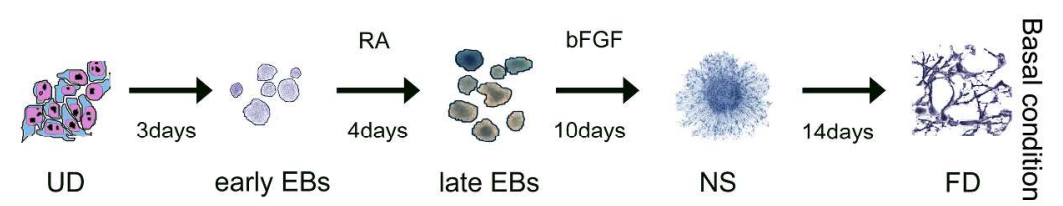

C

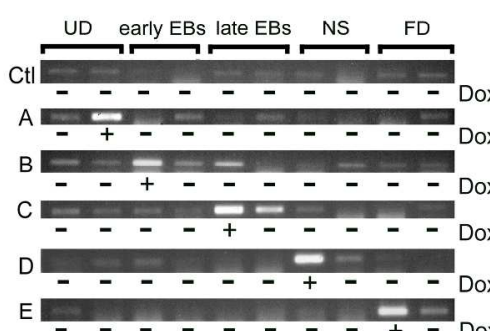

E

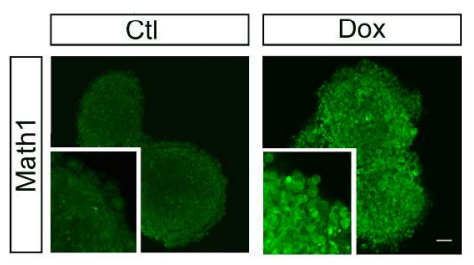

D
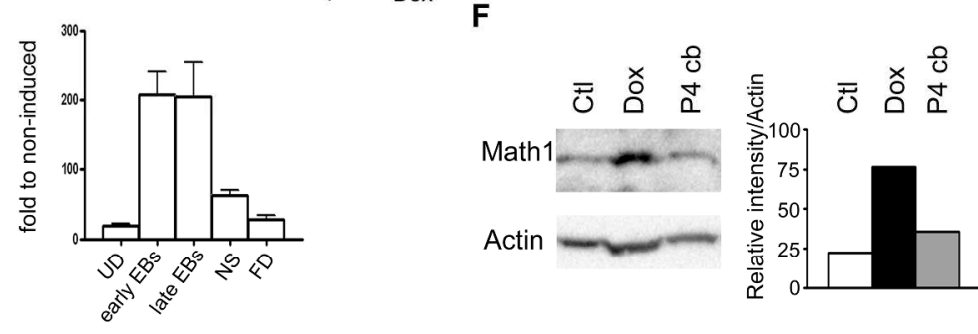

Srivastava et al, Figure 1 
A

$\square$ Mbh1

B

$\square$ Mbh1
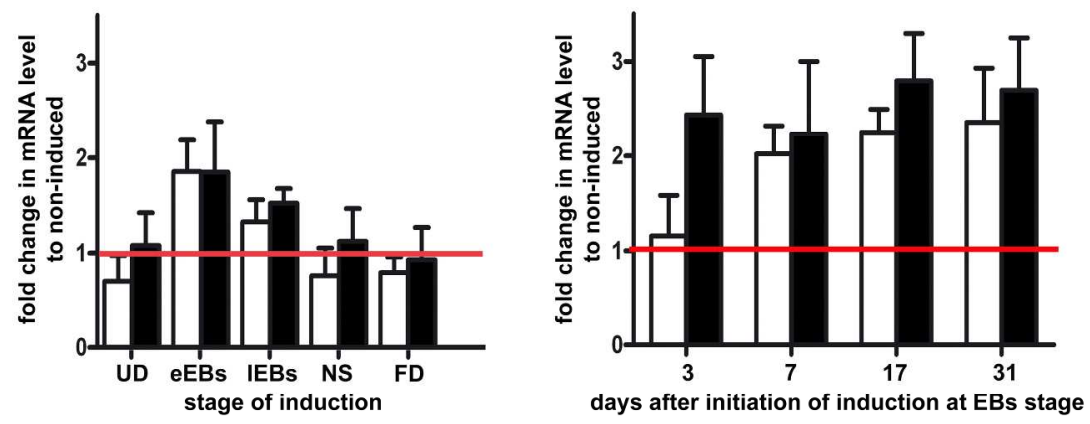

C
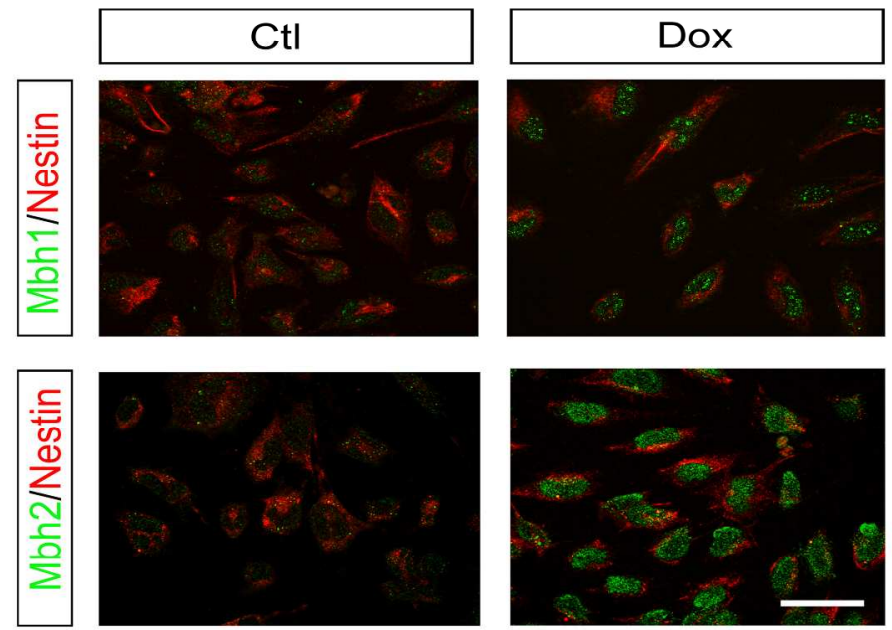

Srivastava et al, Figure 2

$237 \times 281 \mathrm{~mm}(300 \times 300$ DPI $)$ 
A
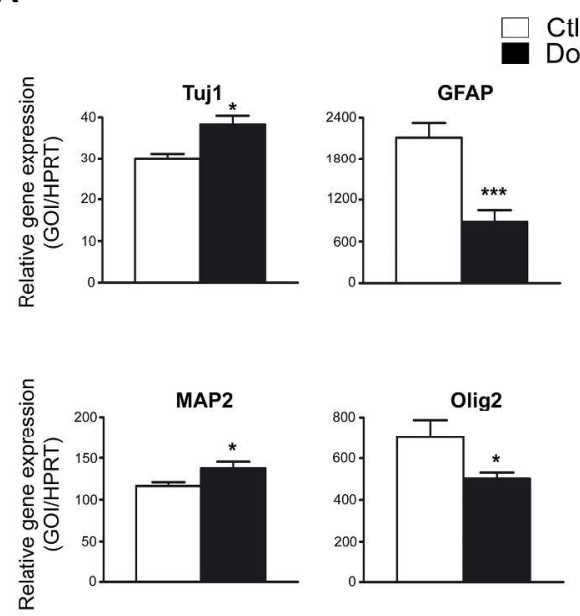

C

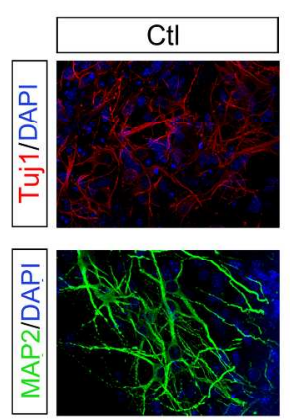

B
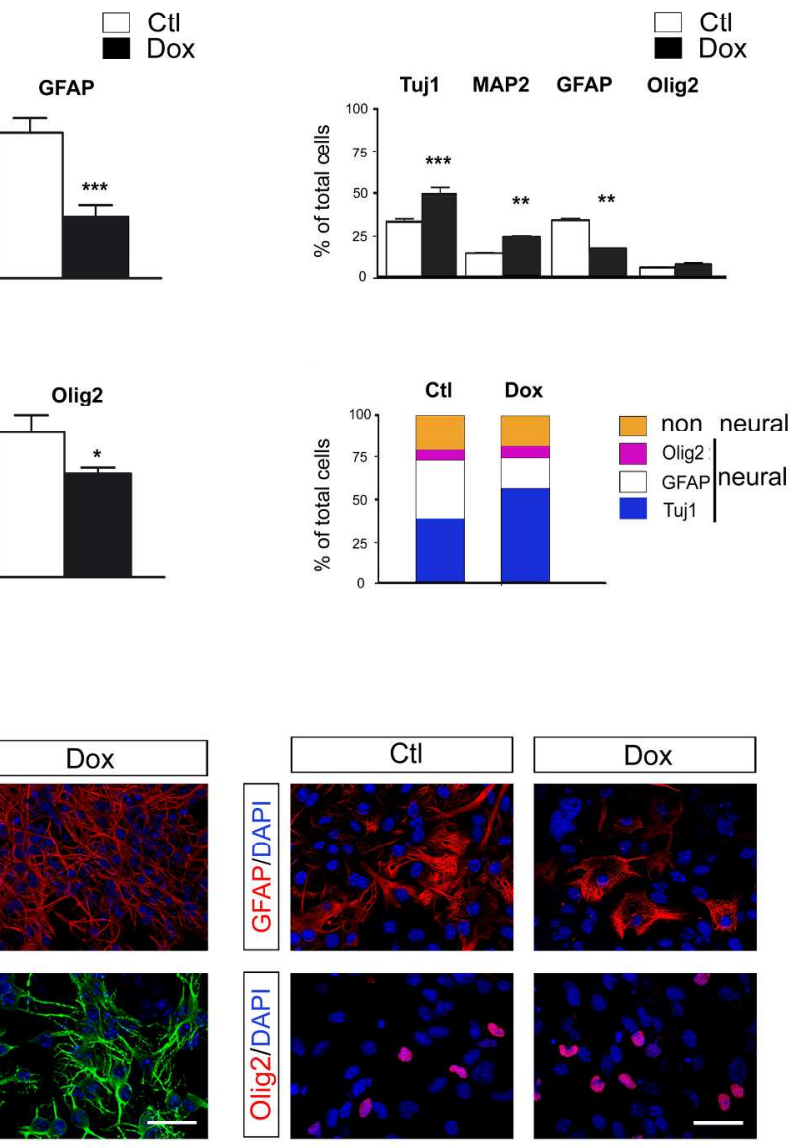

Srivastava et al, Figure 3

$231 \times 268 \mathrm{~mm}(300 \times 300$ DPI $)$ 
A

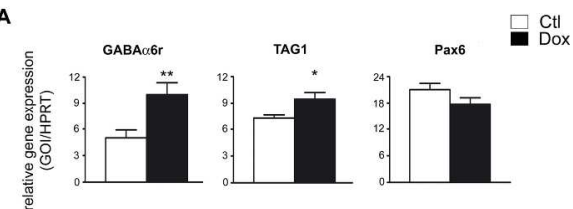

同11

B
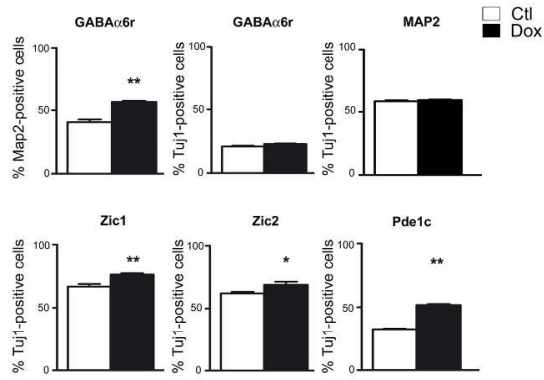

C
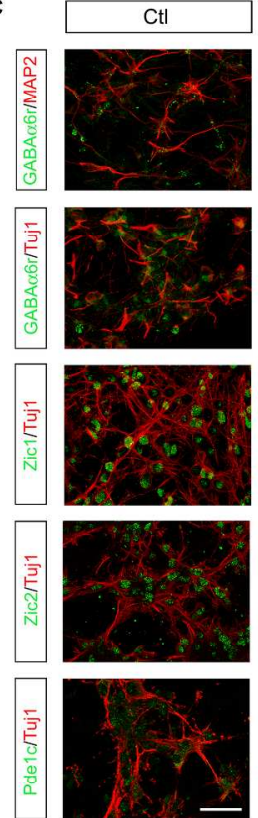
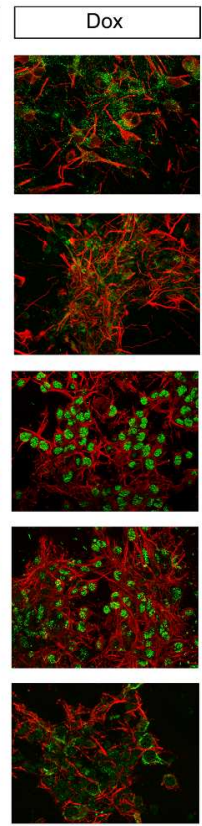

Srivastava et al, Figure 4

$228 \times 167 \mathrm{~mm}(300 \times 300$ DPI $)$ 
A

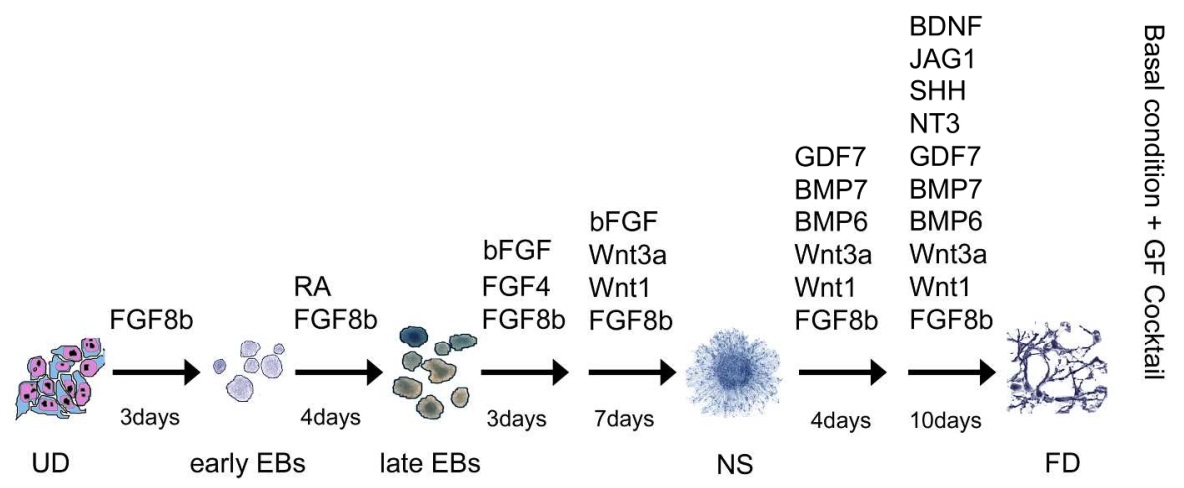

B

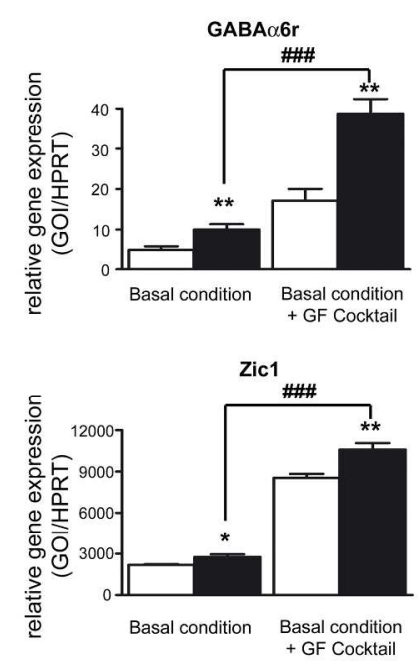

C
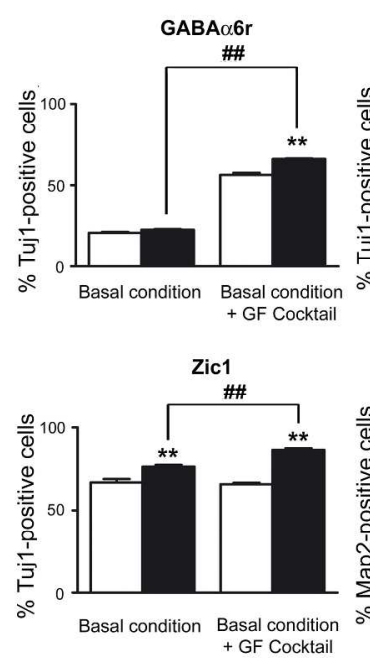
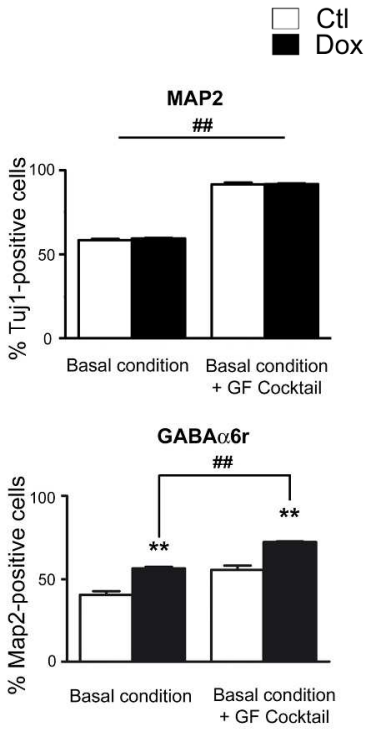

Srivastava et al, Figure 5 
A
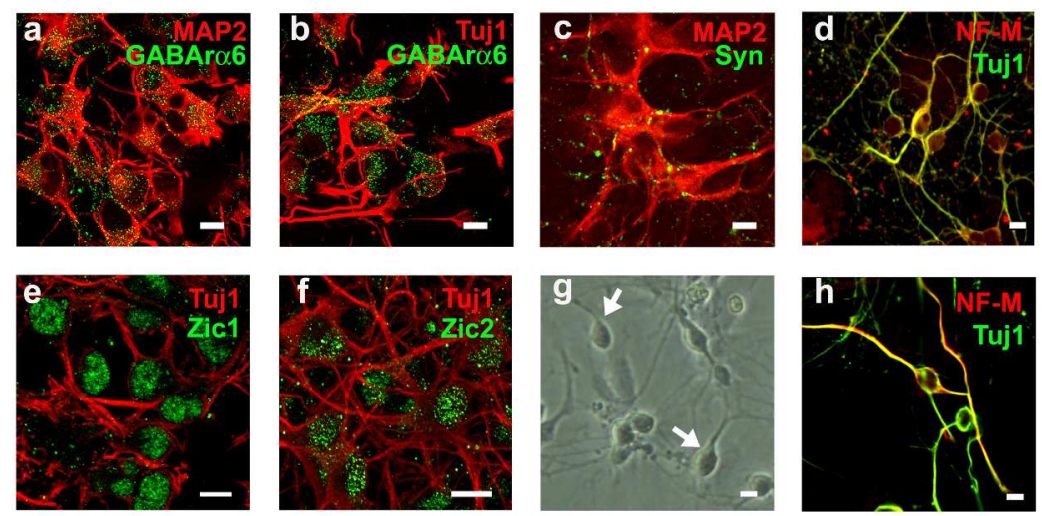

B

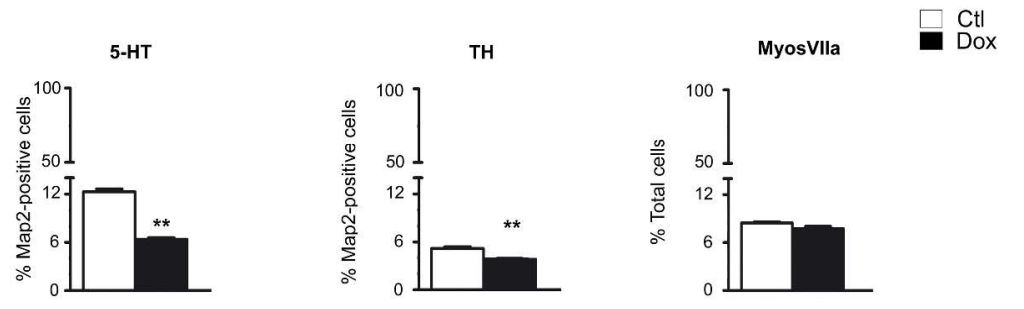

C

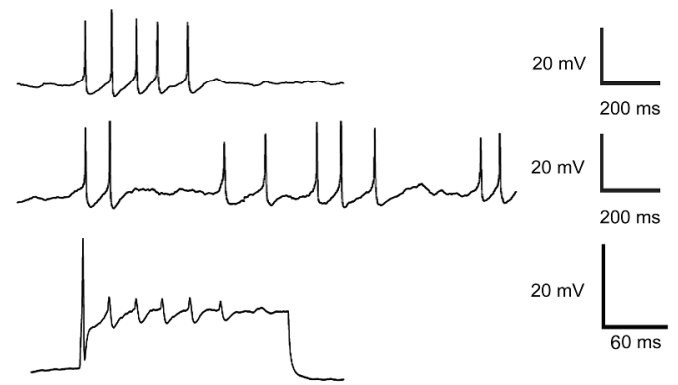

Srivastava et al, Figure 6

$288 \times 400 \mathrm{~mm}(300 \times 300$ DPI $)$ 


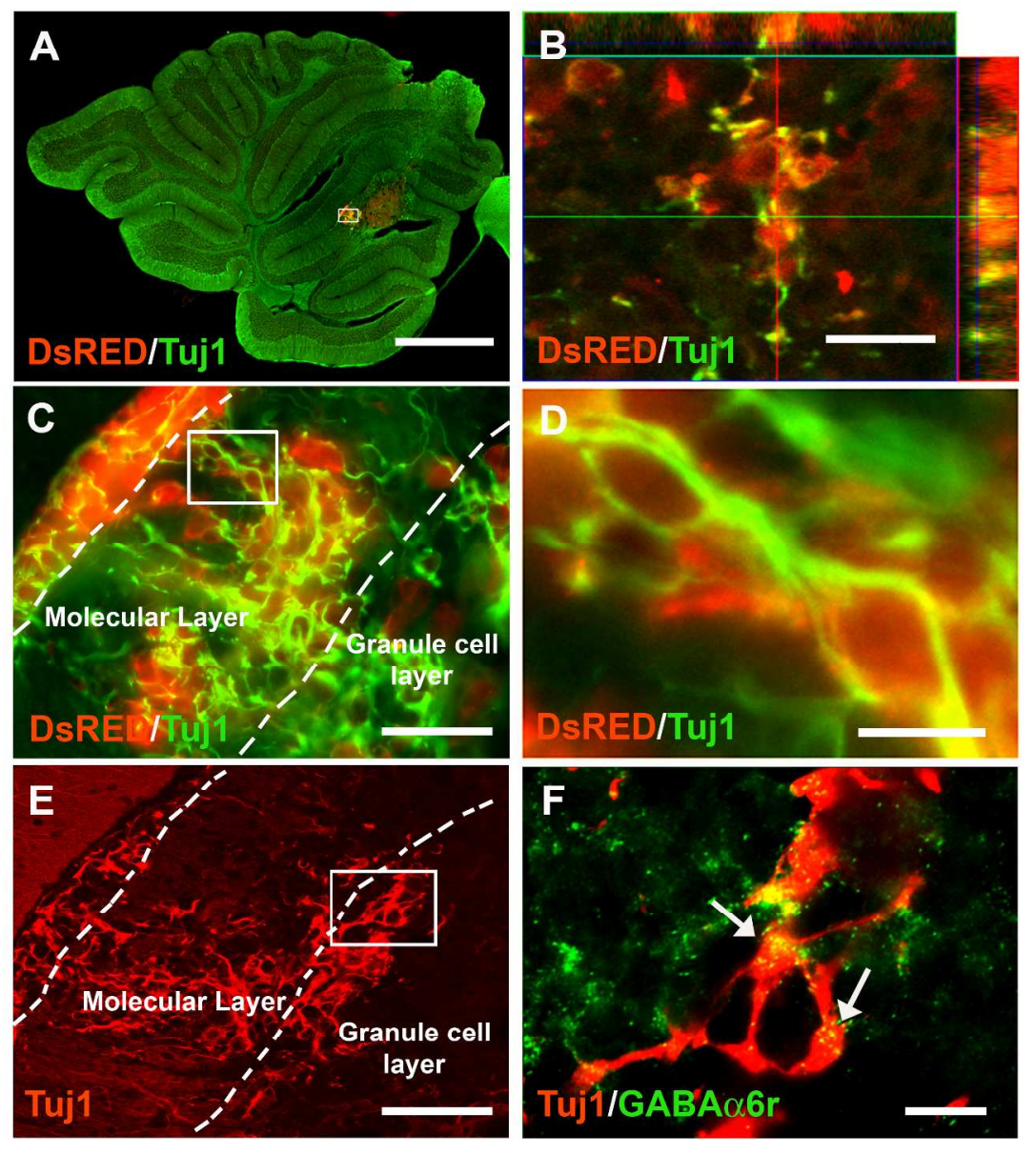

Srivastava et al, Figure 7

$293 \times 350 \mathrm{~mm}(300 \times 300$ DPI $)$ 


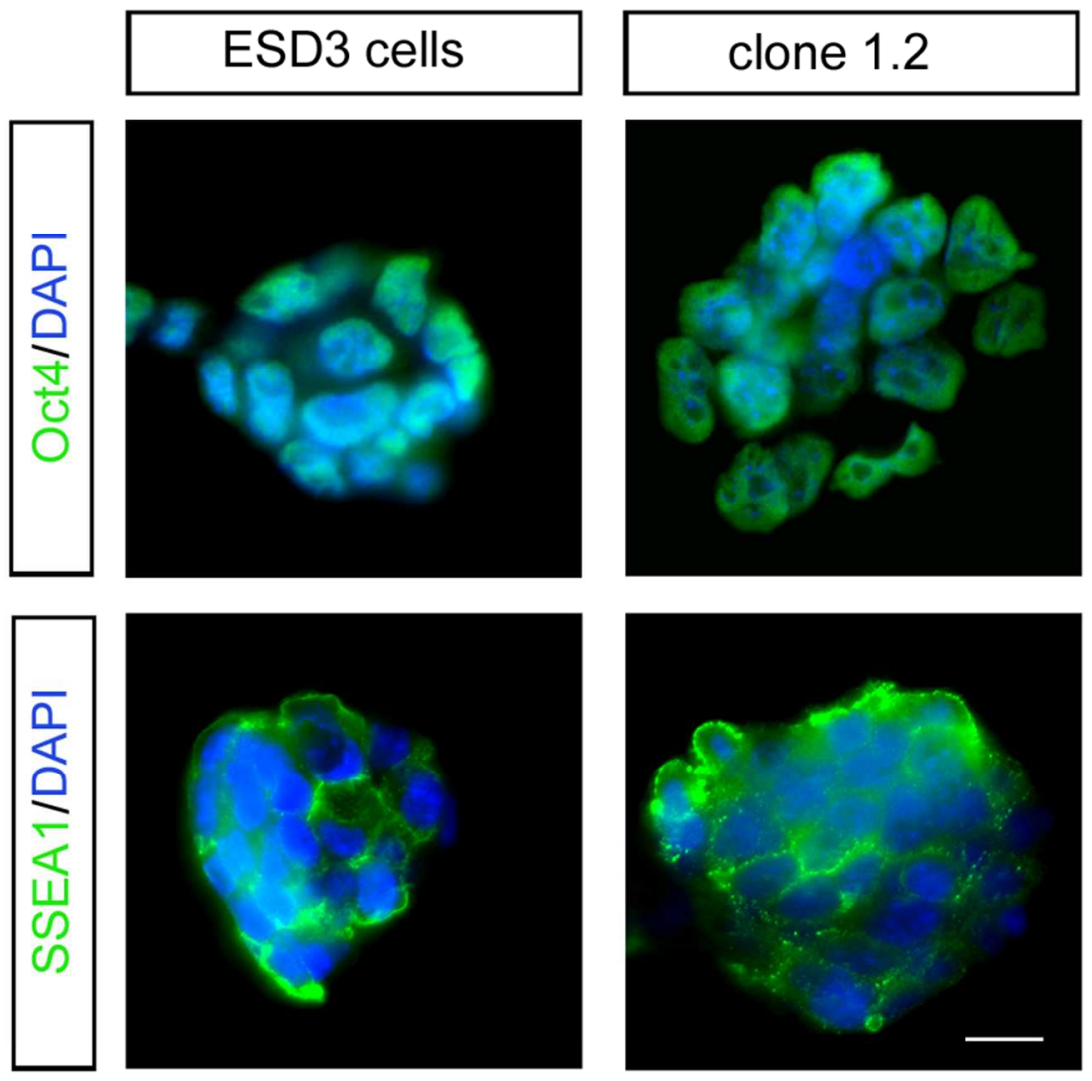

Srivastava et al, Supporting Information Figure 1 
A
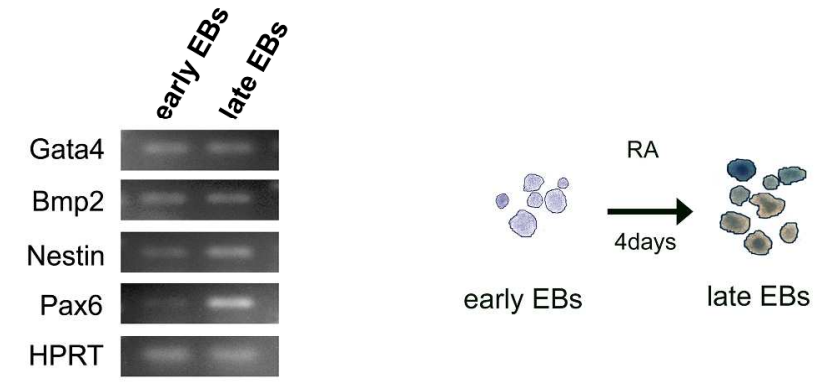

B
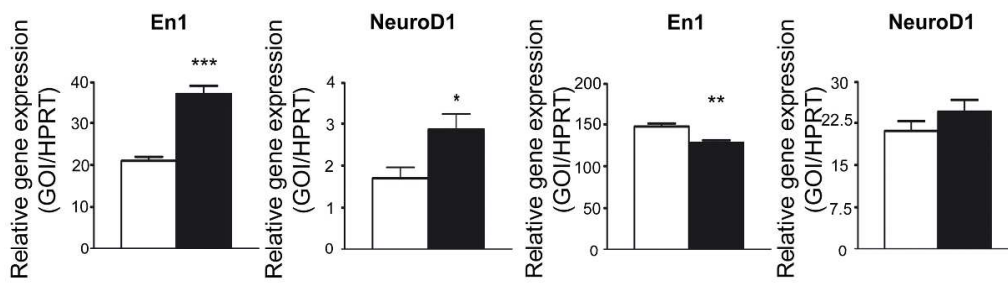

late EBs stage

FD stage

C

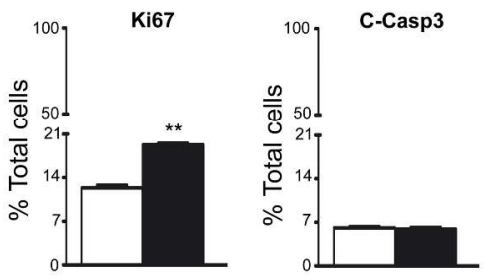

late EBs stage
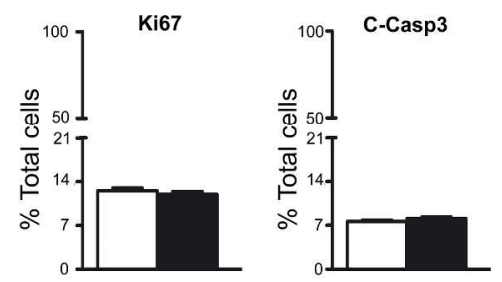

NS stage

Srivastava et al, Supporting Information Figure 2 
A

A
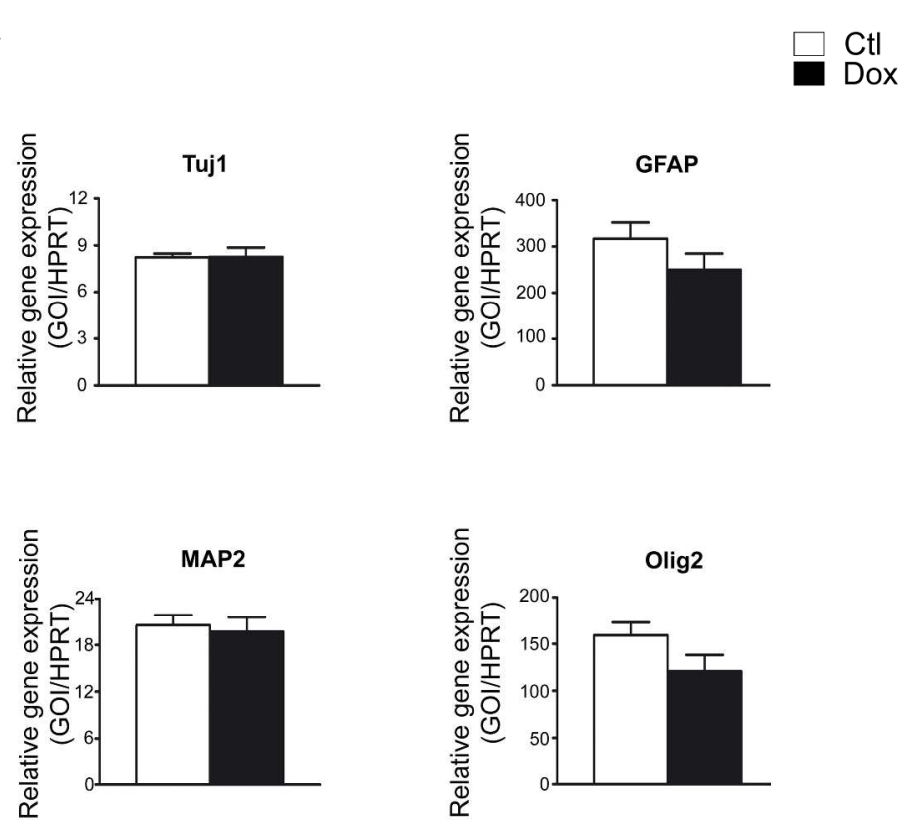

B

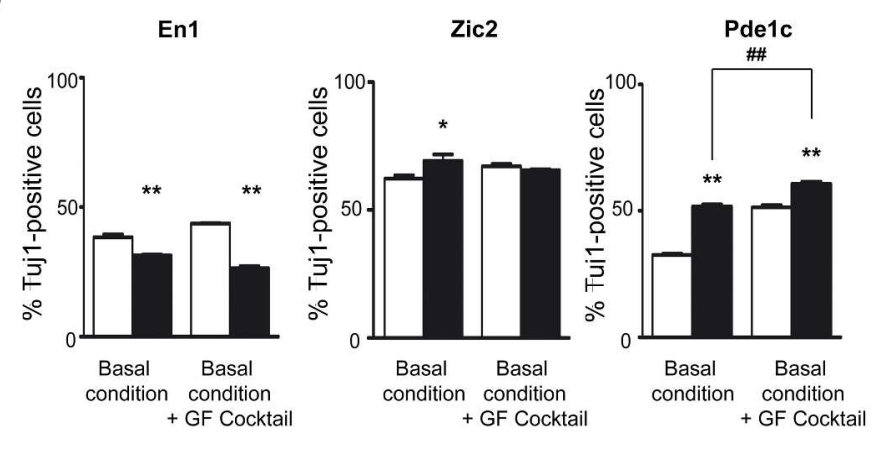

Srivastava et al, Supporting Information Figure 3

$212 \times 308 \mathrm{~mm}(300 \times 300$ DPI $)$ 
A

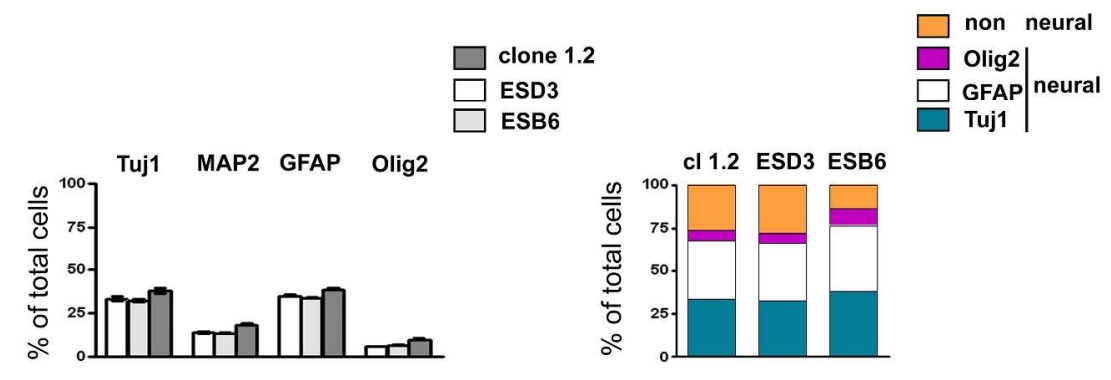

B
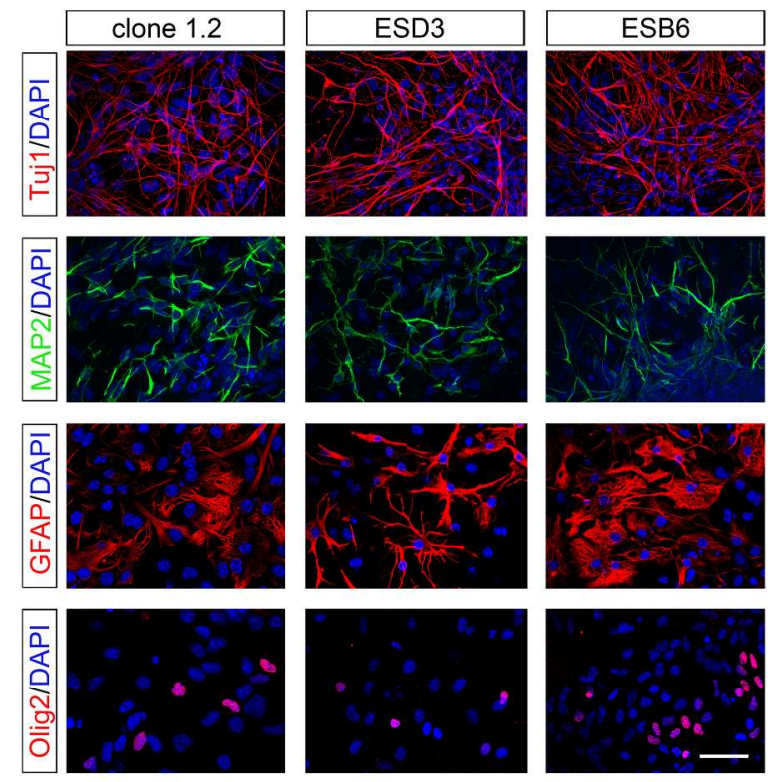

Srivastava et al, Supporting Information Figure 4 


\section{Page 39 of 67}

A

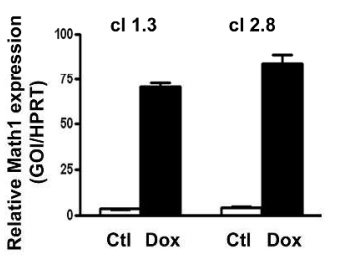

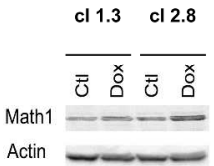

B

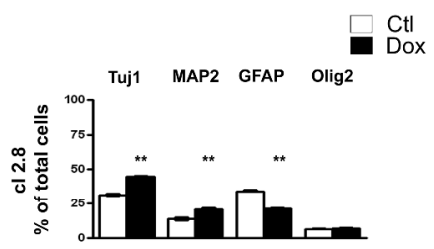

C
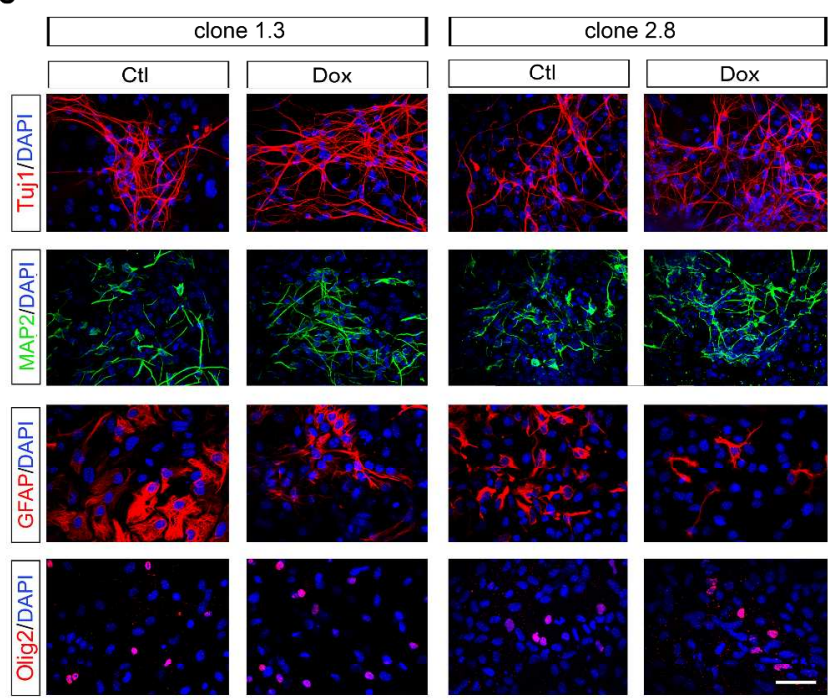

Srivastava et al, Supporting Information Figure 5

$293 \times 492 \mathrm{~mm}(300 \times 300$ DPI $)$ 
A

clone 1.3

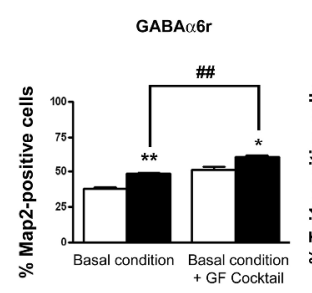

Zic1

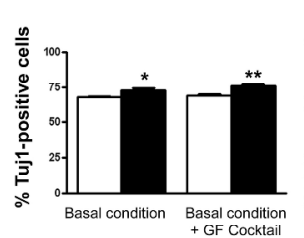

GF Cocktail

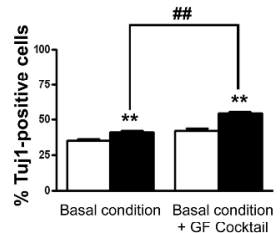

Basal condititon
$+G F$ Cocktail

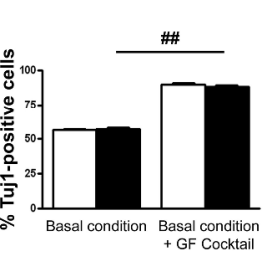

Pde1c

B
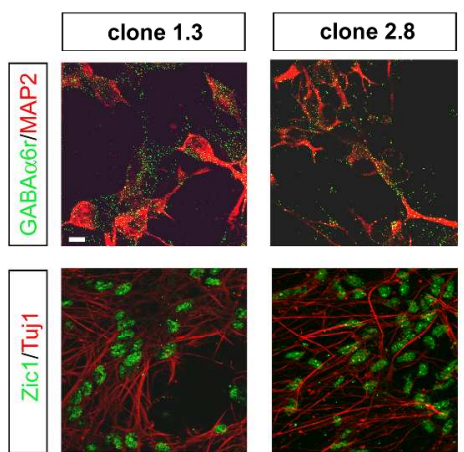

\begin{tabular}{|l}
\hline$\frac{5}{3}$ \\
$\frac{5}{0}$ \\
$\frac{0}{0}$ \\
0 \\
\hline
\end{tabular}
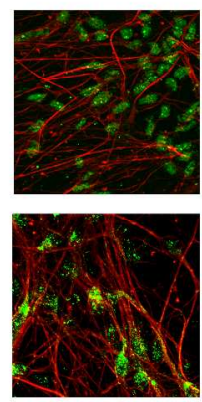

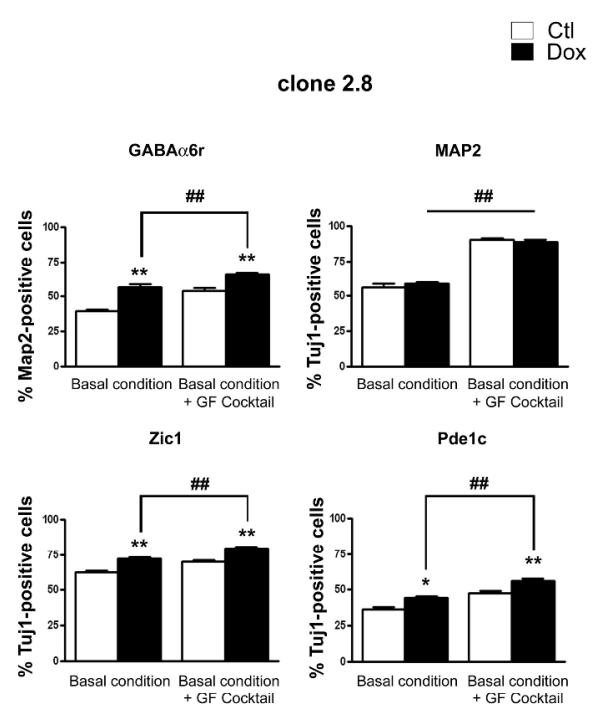

C
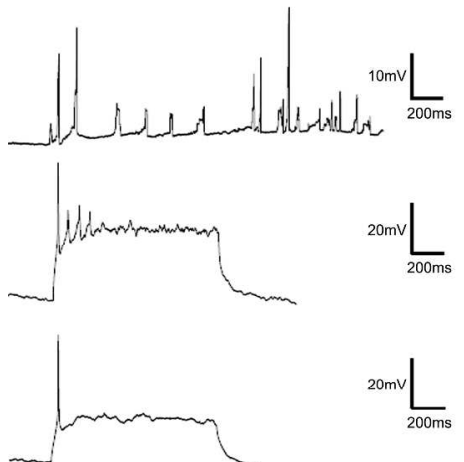

Srivastava et al, Supporting Information Figure 6

$295 \times 377 \mathrm{~mm}(300 \times 300$ DPI $)$ 
Positive Control
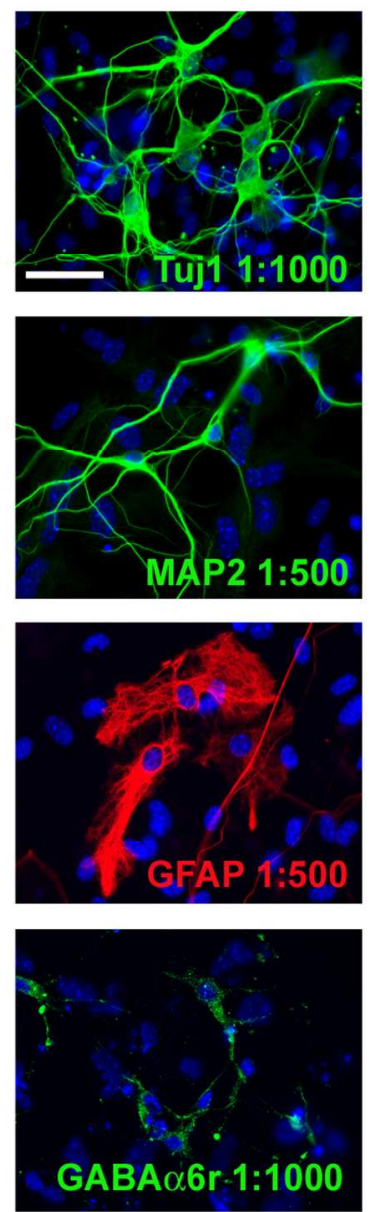

GABA $\alpha 6 r-1: 1000$
Negative Control
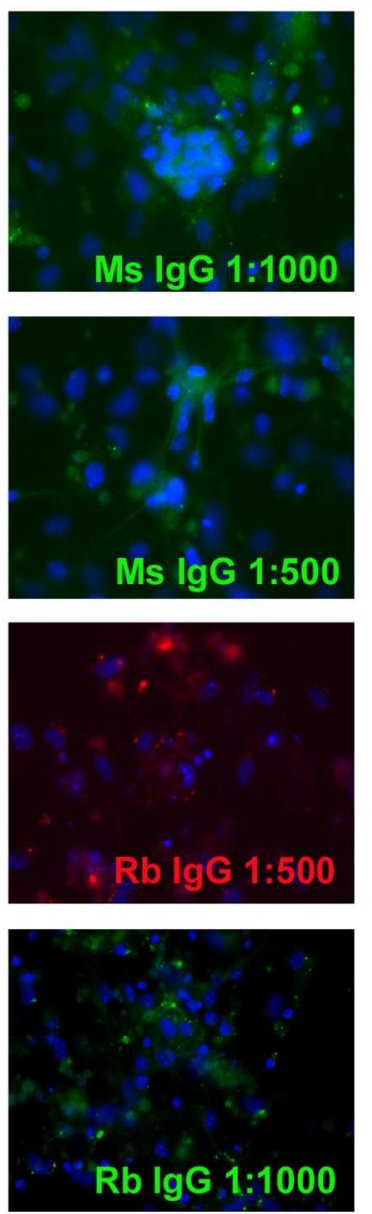

Srivastava et al, Supporting Information Figure 7

$154 \times 272 \mathrm{~mm}(150 \times 150 \mathrm{DPI})$ 